\title{
Solid acid proton conductors: from laboratory curiosities to fuel cell electrolytes
}

\author{
Sossina M. Haile,* Calum R. I. Chisholm, $\dagger$ Kenji Sasaki, \\ Dane A. Boysen $\nmid$ and Tetsuya Uda $\ddagger$
}

\author{
Received 24th March 2006, Accepted 4th May 2006 \\ First published as an Advance Article on the web 7th August 2006 \\ DOI: $10.1039 / b 604311 a$
}

The compound $\mathrm{CsH}_{2} \mathrm{PO}_{4}$ has emerged as a viable electrolyte for intermediate temperature $\left(200-300{ }^{\circ} \mathrm{C}\right)$ fuel cells. In order to settle the question of the high temperature behavior of this material, conductivity measurements were performed by two-point AC impedance spectroscopy under humidified conditions $\left(\mathrm{p}\left[\mathrm{H}_{2} \mathrm{O}\right]=0.4 \mathrm{~atm}\right)$. A transition to a stable, high conductivity phase was observed at $230{ }^{\circ} \mathrm{C}$, with the conductivity rising to a value of $2.2 \times 10^{-2} \mathrm{~S} \mathrm{~cm}^{-1}$ at $240{ }^{\circ} \mathrm{C}$ and the activation energy of proton transport dropping to $0.42 \mathrm{eV}$. In the absence of active humidification, dehydration of $\mathrm{CsH}_{2} \mathrm{PO}_{4}$ does indeed occur, but, in contradiction to some suggestions in the literature, the dehydration process is not responsible for the high conductivity at this temperature.

Electrochemical characterization by galvanostatic current interrupt (GCI) methods and three-point AC impedance spectroscopy (under uniform, humidified gases) of $\mathrm{CsH}_{2} \mathrm{PO}_{4}$ based fuel cells, in which a composite mixture of the electrolyte, Pt supported on carbon, Pt black and carbon black served as the electrodes, showed that the overpotential for hydrogen electrooxidation was virtually immeasurable. The overpotential for oxygen electroreduction, however, was found to be on the order of $100 \mathrm{mV}$ at $100 \mathrm{~mA} \mathrm{~cm}{ }^{-2}$. Thus, for fuel cells in which the supported electrolyte membrane was only $25 \mu \mathrm{m}$ in thickness and in which a peak power density of $415 \mathrm{~mW} \mathrm{~cm}^{-2}$ was achieved, the majority of the overpotential was found to be due to the slow rate of oxygen electrocatalysis. While the much faster kinetics at the anode over those at the cathode are not surprising, the result indicates that enhancing power output beyond the present levels will require improving cathode properties rather than further lowering the electrolyte thickness. In addition to the characterization of the transport and electrochemical properties of $\mathrm{CsH}_{2} \mathrm{PO}_{4}$, a discussion of the entropy of the superprotonic transition and the implications for proton transport is presented.

\section{Introduction}

Solid acid proton conductors, based on tetrahedral oxyanion groups, have received attention as electrolytes in next generation fuel cells. Compounds within this class,

\footnotetext{
Materials Science, California Institute of Technology, Pasadena CA 91125, USA. E-mail: smhaile@caltech.edu
$\uparrow$ Present Address: SuperProtonic Inc. Pasadena, CA 91101, USA.
\$ Present Address: Materials Science and Engineering, Kyoto University, Sakyo, Kyoto 6068501, Japan.
} 
such as $\mathrm{CsHSO}_{4},{ }^{1} \mathrm{Rb}_{3} \mathrm{H}\left(\mathrm{SeO}_{4}\right)_{2},{ }^{2}$ and $\left(\mathrm{NH}_{4}\right)_{3} \mathrm{H}\left(\mathrm{SO}_{4}\right)_{2},{ }^{3}$ exhibit anhydrous proton transport with conductivities of the order of $10^{-3}$ to $10^{-2} \mathrm{~S} \mathrm{~cm}^{-1}$ at moderate temperatures $\left(120-300{ }^{\circ} \mathrm{C}\right)$. Unlike the polymers in more conventional proton exchange membrane fuel cells (PEMFCs), proton conduction in oxyanion solid acids does not rely on the migration of hydronium ions. Consequently, the requirement for humidification of the electrolyte is, in principle, eliminated as is the need for delicate water management. ${ }^{4}$ The temperatures of operation accessible to fuel cells based on solid acids furthermore imply that catalysis rates will be enhanced relative to PEMFCs, opening up possibilities for reduction in precious metal loadings or even the elimination of precious metals entirely. These temperatures additionally imply a high tolerance of the catalysts to poisons, particularly $\mathrm{CO}$, in the fuel stream. While these many features render solid acids very attractive as fuel cell electrolytes several challenges must be addressed in technologically relevant fuel cell systems. Prominent amongst these is the water solubility of all known solid acids with high conductivity, which requires the implementation of engineering designs to prevent condensed water from contacting the electrolyte, particularly during fuel cell shutdown.

In contrast to the application potential of solid acid proton conductors, which has been explored over only the past five years, ${ }^{4}$ the fundamental physical and chemical characteristics of these materials have been studied for well over twenty years. This is a consequence of the fascinating sequence of phase transitions that occur in these compounds in response to heating, cooling or application of pressure. In general, these transitions involve changes to the network of hydrogen bonds which link the oxyanion groups to form dimers, chains, layers, or three-dimensional structures. In the particular case of proton transport, the dynamic disordering of the hydrogen bond network above the so-called superprotonic transition leads to a dramatic increase in proton conductivity by several orders of magnitude. ${ }^{1-3,5}$ Subtle changes in the local hydrogen bond geometry similarly give rise to the well-known ferroelectric transition in compounds such as $\mathrm{KH}_{2} \mathrm{PO}_{4}{ }^{6}$ and $\mathrm{Cs}_{3} \mathrm{H}\left(\mathrm{SeO}_{4}\right)_{2}{ }^{7}$ This rich phase behavior has spawned the production of at least 500 papers that broadly address solid acids with stoichiometry $\mathrm{MHXO}_{4}, \mathrm{M}_{3} \mathrm{H}\left(\mathrm{XO}_{4}\right)_{2}, \mathrm{M}_{2} \mathrm{H}\left(\mathrm{X}^{\prime} \mathrm{O}_{4}\right)$, or some variation thereof, where $\mathrm{M}=$ alkali metal or $\mathrm{NH}_{4} ; \mathrm{X}=\mathrm{S}$, Se; and $\mathrm{X}^{\prime}=\mathrm{P}$, As.

In this work we review the scientific and technological status of selected solid acids, with emphasis on recent developments in the authors' laboratory in the study of $\mathrm{CsH}_{2} \mathrm{PO}_{4}$. After addressing the ongoing literature controversy regarding the high temperature properties of this material, in particular, the nature of the transformation occurring at approximately $230{ }^{\circ} \mathrm{C}$, we present new data supporting the position that a true polymorphic transition occurs in this material. We then evaluate the behavior of $\mathrm{CsH}_{2} \mathrm{PO}_{4}$ as a fuel cell electrolyte, examining the relative rates of hydrogen electrooxidation and oxygen electroreduction. We then close with a speculative discussion of the configurational entropy of the high temperature phase of $\mathrm{CsH}_{2} \mathrm{PO}_{4}$, in which we propose that the disorder associated with the hydrogen bond network should be considered independently of the oxyanion group disorder. Thus, despite its rather innocent chemical formula, $\mathrm{CsH}_{2} \mathrm{PO}_{4}$ provides a rich variety of scientific challenges and technological opportunities.

\section{Phase transition behavior}

\section{The literature debate}

The controversy surrounding the high temperature properties of $\mathrm{CsH}_{2} \mathrm{PO}_{4}$ stem from the decomposition behavior of the material. Specifically, it has been argued by some that the dehydration of the compound

$$
\mathrm{CsH}_{2} \mathrm{PO}_{4}(\mathrm{~s}) \rightarrow \mathrm{CsH}_{2-2 x} \mathrm{PO}_{4-x}(\mathrm{~s})+x \mathrm{H}_{2} \mathrm{O}(\mathrm{g}),(0 \leq x \leq 1) \rightarrow \mathrm{CsPO}_{3}+\mathrm{H}_{2} \mathrm{O}(x=1)
$$

induces a transient rise in conductivity as water leaves the structure, but that there is no true polymorphic transition to a high conductivity phase. Others, however, have 
argued that, while decomposition can interfere with the observation of the polymorphic transition, it nevertheless occurs. A selection of the relevant papers documenting this controversy is provided in Table 1, along with a notation indicating whether the paper supports, refutes or remains neutral on the matter of a superprotonic phase transition.

The early thermal analyses of $\mathrm{CsH}_{2} \mathrm{PO}_{4}$ were very much in contradiction with one another. The first papers on the topic of the thermal behavior of $\mathrm{CsH}_{2} \mathrm{PO}_{4}$ (beyond simple weight loss measurements) appear to be two reports from Rashkovich et al., and even these are in disagreement. The earlier paper concludes that two transitions occur prior to decomposition, ${ }^{8}$ whereas the latter concludes that the thermal events are entirely due to decomposition. ${ }^{9}$ In two papers co-authored by Clark, two polymorphic transitions are reported for $\mathrm{CsH}_{2} \mathrm{PO}_{4} \cdot{ }^{10,11}$ The latter, occurring at $230{ }^{\circ} \mathrm{C}$, was found to be fully reversible. However, it was associated with a slight weight loss $(\sim 1.5 \%)$ for powder samples examined under ambient conditions. This feature would become the point of significant controversy in later years. Wada subsequently confirmed the $230{ }^{\circ} \mathrm{C}$ transition by dilatometry measurements of single crystal samples, observing a sharp increase in lattice constants at this temperature. ${ }^{12}$ Almost simultaneously, Gupta reported, again on the basis of calorimetry and thermal gravimetric analysis, a polymorphic transition in $\mathrm{CsH}_{2} \mathrm{PO}_{4}$ at $235{ }^{\circ} \mathrm{C}$ just prior to the maximum in the decomposition process. ${ }^{13}$ Again, however, initiation of the weight loss coincided with the reported polymorphic transition. In contradiction to these results, Nirsha et al. published a study two years later concluding that thermal events at $233{ }^{\circ} \mathrm{C}$ and higher in $\mathrm{CsH}_{2} \mathrm{PO}_{4}$ are entirely due to decomposition. ${ }^{14}$

The matter of a polymorphic phase transition in $\mathrm{CsH}_{2} \mathrm{PO}_{4}$ may have remained an obscure point in the field of solid state chemistry were it not for the results of Baranov et al. showing a so-called superprotonic transition to occur at $230{ }^{\circ} \mathrm{C},{ }^{5}$ precisely the temperature of the reversible, higher temperature transformation first reported by Clark. ${ }^{10,11}$ The conductivity was shown to increase by five orders of magnitude at the transition, and apparently reliable data were obtained to temperatures of $\sim 250{ }^{\circ} \mathrm{C}$. In hindsight, it is clear that Baranov was able to observe the transition because single crystals, in which dehydration is slow compared to powdered materials, were utilized for the experiments. Shortly after Baranov's study, Bronowska and Pietraszko reported the structure of superprotonic $\mathrm{CsH}_{2} \mathrm{PO}_{4}$ and provided the first clear demonstration of the significance of water partial pressure in suppressing dehydration. ${ }^{15}$ All of the peaks in the high temperature X-ray powder diffraction pattern, along with their relative intensities, could be explained on the basis of the proposed high temperature structure. The subsequent Raman study of Romain and Novak ${ }^{16}$ supported Bronowska's conclusions regarding the structural features of the superprotonic state, while Vargas and Torijano in 1993 also agreed (initially) with the existence of a reversible, but hysteretic, phase transition at $227{ }^{\circ} \mathrm{C}$ on the basis of differential scanning calorimetry. ${ }^{17}$

The controversy surrounding the properties of $\mathrm{CsH}_{2} \mathrm{PO}_{4}$ began in earnest in 1996 with a publication by Lee suggesting that the observed conductivity effects were artifacts of thermal decomposition and partial polymerization at the surfaces of the $\mathrm{CsH}_{2} \mathrm{PO}_{4}$ particles. ${ }^{19}$ The hypothesis was based on a review of literature data, without the benefit of new experimental results. A later paper from this same author repeated these conclusions, but in this case experimental support was provided in the form of a limited set of optical micrographs showing the degradation of single crystal surfaces. ${ }^{24}$ Inspired by Lee's work, Ortiz, Vargas and Mellander published a series of papers also taking the view that only decomposition occurs at the supposed superprotonic transition. ${ }^{21,22,33}$ In this case, the conclusions were based on thermal analysis and high temperature X-ray diffraction experiments performed on powdered samples and on conductivity measurements performed on single crystal samples. Thermal events were found to coincide with weight loss events, increases in conductivity at $230{ }^{\circ} \mathrm{C}$ were found to diminish in significance with repeated thermal cycling, and the high temperature diffraction data showed a rather messy 
Table 1 Selected publications describing the high-temperature structural and/or transport properties of $\mathrm{CsH}_{2} \mathrm{PO}_{4} . \mathrm{S}=$ supporting the conclusion of a superprotonic transition; $\mathrm{R}=$ refuting the conclusion; and ? = uncommitted

\begin{tabular}{|c|c|c|c|c|}
\hline Authors & Article Title & Year & Ref. & $\mathrm{S} / \mathrm{R} / ?^{*}$ \\
\hline $\begin{array}{l}\text { L. N. Rashkovich, K. B. } \\
\text { Meteva, Ya. É. Shevchik, } \\
\text { V. G. Hoffman, and } \\
\text { A. V. Mishchenko }\end{array}$ & $\begin{array}{l}\text { Growing Single Crystals of } \\
\text { Cesium Dihydrogen } \\
\text { Phosphate and Some of Their } \\
\text { Properties. }\end{array}$ & 1977 & 8 & $\mathrm{~S} ?$ \\
\hline $\begin{array}{l}\text { L. N. Rashkovich and } \\
\text { K. B. Meteva }\end{array}$ & $\begin{array}{l}\text { Properties of Cesium } \\
\text { Dihydrophosphate. }\end{array}$ & 1978 & 9 & $\mathrm{R}$ \\
\hline $\begin{array}{l}\text { E. Rapoport, J. B. Clark } \\
\text { and P. W. Richter }\end{array}$ & $\begin{array}{l}\text { High-Pressure Phase } \\
\text { Relations of } \mathrm{RbH}_{2} \mathrm{PO}_{4} \text {, } \\
\mathrm{CsH}_{2} \mathrm{PO}_{4} \text {, and } \mathrm{KD}_{2} \mathrm{PO}_{4} \text {. }\end{array}$ & 1978 & 10 & $\mathrm{~S}$ \\
\hline B. Metcalfe and J. B. Clark & $\begin{array}{l}\text { Differential Scanning } \\
\text { Calorimetry of } \mathrm{RbH}_{2} \mathrm{PO}_{4} \text { and } \\
\mathrm{CsH}_{2} \mathrm{PO}_{4} \text {. }\end{array}$ & 1978 & 11 & $\mathrm{~S}$ \\
\hline $\begin{array}{l}\text { M. Wada, A. Sawada and } \\
\text { Y. Ishibashi }\end{array}$ & $\begin{array}{l}\text { Some High-Temperature } \\
\text { Properties and the Raman- } \\
\text { Scattering Spectra of } \\
\mathrm{CsH}_{2} \mathrm{PO}_{4} \text {. }\end{array}$ & 1979 & 12 & $\mathrm{~S}$ \\
\hline $\begin{array}{l}\text { L. C. Gupta, U. R. K. Rao, } \\
\text { K. S. Venkateswarlu and } \\
\text { B. R. Wani }\end{array}$ & $\begin{array}{l}\text { Thermal-Stability of } \\
\mathrm{CsH}_{2} \mathrm{PO}_{4} \text {. }\end{array}$ & 1980 & 13 & $\mathrm{~S}$ \\
\hline $\begin{array}{l}\text { B. M. Nirsha, E. N. } \\
\text { Gudinitsa, A. A. Fakeev, V. } \\
\text { A. Efremov, B. V. Zhadanov } \\
\text { and V. A. Olikova }\end{array}$ & $\begin{array}{l}\text { Thermal Dehydration Process } \\
\text { of } \mathrm{CsH}_{2} \mathrm{PO}_{4} \text {. }\end{array}$ & 1982 & 14 & $\mathrm{R}$ \\
\hline $\begin{array}{l}\text { A. I. Baranov, V. P. } \\
\text { Khiznichenko, V. A. Sandler } \\
\text { and L. A. Shuvalov }\end{array}$ & $\begin{array}{l}\text { Frequency Dielectric- } \\
\text { Dispersion in the } \\
\text { Ferroelectric and Superionic } \\
\text { Phases of } \mathrm{CsH}_{2} \mathrm{PO}_{4} \text {. }\end{array}$ & 1988 & 5 & $\mathrm{~S}$ \\
\hline $\begin{array}{l}\text { W. Bronowska and } \\
\text { A. Pietraszko }\end{array}$ & $\begin{array}{l}\text { X-Ray Study of the High- } \\
\text { Temperature Phase- } \\
\text { Transition of } \mathrm{CsH}_{2} \mathrm{PO}_{4} \\
\text { Crystals. }\end{array}$ & 1990 & 15 & $\mathrm{~S}$ \\
\hline F. Romain and A. Novak & $\begin{array}{l}\text { Raman Study of the High- } \\
\text { Temperature } \mathrm{Phase}^{-} \\
\text {Transition in } \mathrm{CsH}_{2} \mathrm{PO}_{4} \text {. }\end{array}$ & 1991 & 16 & $\mathrm{~S}$ \\
\hline R. A. Vargas and E. Torijano & $\begin{array}{l}\text { Phase-Behavior of } \mathrm{RbH}_{2} \mathrm{PO}_{4} \\
\text { and } \mathrm{CsH}_{2} \mathrm{PO}_{4} \text { in the Fast-Ion } \\
\text { Regime. }\end{array}$ & 1993 & 17 & S? \\
\hline $\begin{array}{l}\text { A. Preisinger, K. Mereiter, } \\
\text { and W. Bronowska }\end{array}$ & $\begin{array}{l}\text { The Phase Transition of } \\
\mathrm{CsH}_{2} \mathrm{PO}_{4}(\mathrm{CDP}) \text { at } 505 \mathrm{~K} \text {. }\end{array}$ & 1994 & 18 & $\mathrm{~S}$ \\
\hline K. S. Lee & $\begin{array}{l}\text { Hidden Nature of the High- } \\
\text { Temperature Phase } \\
\text { Transitions in Crystals of } \\
\mathrm{KH}_{2} \mathrm{PO}_{4} \text {-Type: Is It a } \\
\text { Physical Change? }\end{array}$ & 1996 & 19 & $\mathrm{R}$ \\
\hline $\begin{array}{l}\text { Y. Luspin, Y, Vaills, and } \\
\text { G. Hauret }\end{array}$ & $\begin{array}{l}\text { Discontinuities in the Elastic } \\
\text { Properties of } \mathrm{CsH}_{2} \mathrm{PO}_{4} \text { at the } \\
\text { Superionic Transition. }\end{array}$ & 1997 & 20 & S \\
\hline $\begin{array}{l}\text { E. Ortiz, R. A. Vargas and } \\
\text { B. E. Mellander }\end{array}$ & $\begin{array}{l}\text { On the High-Temperature } \\
\text { Phase Transitions of } \\
\mathrm{CsH}_{2} \mathrm{PO}_{4} \text { : a Polymorphic } \\
\text { Transition? A Transition to a } \\
\text { Superprotonic Conducting } \\
\text { Phase? }\end{array}$ & 1999 & 21 & $\mathrm{R}$ \\
\hline
\end{tabular}


Table 1 (continued)

\begin{tabular}{|c|c|c|c|c|}
\hline Authors & Article Title & Year & Ref. & $\mathrm{S} / \mathrm{R} /$ ?* $^{*}$ \\
\hline $\begin{array}{l}\text { E. Ortiz, R. A. Vargas and } \\
\text { B. E. Mellander }\end{array}$ & $\begin{array}{l}\text { On the High-Temperature } \\
\text { Phase Transitions of Some } \\
\text { KDP-Family Compounds: a } \\
\text { Structural Phase Transition? } \\
\text { A Transition to a Bulk-High } \\
\text { Proton Conducting Phase? }\end{array}$ & 1999 & 22 & $\mathrm{R}$ \\
\hline W. Bronowska & $\begin{array}{l}\text { Does the Structural } \\
\text { Superionic Phase Transition } \\
\text { at } 231{ }^{\circ} \mathrm{C} \text { in } \mathrm{CsH}_{2} \mathrm{PO}_{4} \text { Really } \\
\text { Not Exist? }\end{array}$ & 2001 & 23 & $\mathrm{~S}$ \\
\hline K. S. Lee & $\begin{array}{l}\text { Surface Transformation of } \\
\text { Hydrogen-Bonded Crystals at } \\
\text { High-Temperatures and } \\
\text { Topochemical Nature. }\end{array}$ & 2002 & 24 & $\mathrm{R}$ \\
\hline $\begin{array}{l}\text { J. Otomo, N. Minagawa, } \\
\text { C. J. Wen, K. Eguchi and } \\
\text { H. Takahashi }\end{array}$ & $\begin{array}{l}\text { Protonic Conduction of } \\
\mathrm{CsH}_{2} \mathrm{PO}_{4} \text { and Its Composite } \\
\text { With Silica in Dry and Humid } \\
\text { Atmospheres. }\end{array}$ & 2003 & 25 & $\mathrm{~S}$ \\
\hline $\begin{array}{l}\text { D. A. Boysen, S. M. Haile, } \\
\text { H. J. Liu and R. A. Secco }\end{array}$ & $\begin{array}{l}\text { High-Temperature Behavior } \\
\text { of } \mathrm{CsH}_{2} \mathrm{PO}_{4} \text { Under Both } \\
\text { Ambient and High Pressure } \\
\text { Conditions. }\end{array}$ & 2003 & 26 & $\mathrm{~S}$ \\
\hline $\begin{array}{l}\text { J. H. Park, C. S. Kim, } \\
\text { B. C. Choi, B. K. Moon and } \\
\text { H. J. Seo }\end{array}$ & $\begin{array}{l}\text { Physical Properties of } \\
\mathrm{CsH}_{2} \mathrm{PO}_{4} \text { Crystal at High } \\
\text { Temperatures. }\end{array}$ & 2003 & 27 & $\mathrm{R}$ \\
\hline $\begin{array}{l}\text { D. A. Boysen, T. Uda, C. R. } \\
\text { I. Chisholm and S. M. Haile }\end{array}$ & $\begin{array}{l}\text { High-Performance Solid Acid } \\
\text { Fuel Cells Through Humidity } \\
\text { Stabilization. }\end{array}$ & 2004 & 28 & $\mathrm{~S}$ \\
\hline J. H. Park & $\begin{array}{l}\text { Possible Origin of the Proton } \\
\text { Conduction Mechanism of } \\
\mathrm{CsH}_{2} \mathrm{PO}_{4} \text { Crystals at High } \\
\text { Temperatures. }\end{array}$ & 2004 & 29 & $\mathrm{R}$ \\
\hline $\begin{array}{l}\text { K. Yamada, T. Sagara, } \\
\text { Y. Yamane, H. Ohki and } \\
\text { T. Okuda }\end{array}$ & $\begin{array}{l}\text { Superprotonic Conductor } \\
\mathrm{CsH}_{2} \mathrm{PO}_{4} \text { Studied by H-1, P- } \\
31 \mathrm{NMR}^{-} \text {and X-Ray } \\
\text { Diffraction. }\end{array}$ & 2004 & 30 & $\mathrm{~S}$ \\
\hline $\begin{array}{l}\text { J. Otomo, T. Tamaki, S. } \\
\text { Nishida, S. Q. Wang, M. } \\
\text { Ogura, T. Kobayashi, C. J. } \\
\text { Wen, H. Nagamoto and } \\
\text { H. Takahashi }\end{array}$ & $\begin{array}{l}\text { Effect of Water Vapor on } \\
\text { Proton Conduction of } \\
\text { Cesium Dihydrogen } \\
\text { Phosphate and Application to } \\
\text { Intermediate Temperature } \\
\text { Fuel Cells. }\end{array}$ & 2005 & 31 & $\mathrm{~S}$ \\
\hline $\begin{array}{l}\text { A. I. Baranov, V. V. } \\
\text { Grebenev, A. N. Khodan, } \\
\text { V. V. Dolbinina and E. P. } \\
\text { Efremova }\end{array}$ & $\begin{array}{l}\text { Optimization of } \\
\text { Superprotonic Acid Salts for } \\
\text { Fuel Cell Applications. }\end{array}$ & 2005 & 32 & $\mathrm{~S}$ \\
\hline
\end{tabular}

evolution of peaks. ${ }^{21}$ From the diffraction data the authors identified what they believed to correspond to the most intense peak of the first dehydration product, however, this peak (at $2 \Theta \approx 25.3^{\circ}$ ) coincides almost precisely with the most intense peak for superprotonic $\mathrm{CsH}_{2} \mathrm{PO}_{4}$, as reported previously by Bronowska et al. ${ }^{18}$ Additional support for the view of dehydration rather than polymorphic phase transitions comes from the work of Park who has published two papers agreeing with the position that only decomposition occurs in $\mathrm{CsH}_{2} \mathrm{PO}_{4}$ upon heating. ${ }^{27,29}$ Here, the conclusion is based primarily on the results of $\mathrm{AC}$ impedance 
measurements performed on single crystals which purportedly show no jump in conductivity at $230{ }^{\circ} \mathrm{C}$. Thermal analysis results are also reported to support the conclusion.

The data analysis methodology employed by Park for interpreting the AC impedance response of $\mathrm{CsH}_{2} \mathrm{PO}_{4}$ requires some comment. In Park's study impedance data were collected over frequency ranges of $1 \mathrm{~Hz}$ to $100 \mathrm{kHz}(2003)^{27}$ and $1 \mathrm{~Hz}$ to $3 \mathrm{MHz}(2004)^{29}$ and the effective dc conductivity was extracted by assuming the measured response to be dominated by the properties of the bulk $\mathrm{CsH}_{2} \mathrm{PO}_{4}$ crystal. However, because the characteristic frequency $\left(\omega_{\mathrm{O}}=1 / \varepsilon_{\mathrm{o}} \varepsilon \rho\right.$, where $\varepsilon_{\mathrm{O}}=$ permittivity of vacuum, $\varepsilon=$ relative dielectric constant, and $\rho=$ resistivity) of $\mathrm{CsH}_{2} \mathrm{PO}_{4}$ rises dramatically at the transition, even at frequencies of $3 \mathrm{MHz}$ one measures, not the bulk properties of the material of interest, but the properties of the electrolyte-electrode interface. In the absence of higher frequency data, one can only estimate the bulk electrolyte properties by extrapolation (typically in the Nyquist, $Z_{\text {real }} v s$. $-Z_{\text {imag }}$ representation) to high frequencies. The situation is illustrated in Fig. 1. The schematic plot in part (a) reflects the kind of data expected when the bulk characteristic frequency of the material of interest is within the experimental measurement range whereas that in part (b) corresponds to that expected when the characteristic frequency is beyond the highest measurement frequency available. Park has essentially treated data of the form shown in Fig. 1(b) by procedures appropriate to data of the form in Fig. 1(a), and, accordingly, that author's conclusion that there is no substantial rise in the conductivity of $\mathrm{CsH}_{2} \mathrm{PO}_{4}$ at $\sim 230{ }^{\circ} \mathrm{C}$ cannot be accepted.

An interesting feature of the argument of those in favor of the dehydration model is that all $\mathrm{MH}_{2} \mathrm{PO}_{4}$ (and indeed $\mathrm{MH}_{2} \mathrm{AsO}_{4}$ ) compounds are assumed to exhibit identical high temperature behavior. That is, it is assumed that if dehydration can be demonstrated in the case, for example, of $\mathrm{KH}_{2} \mathrm{PO}_{4}$, this implies dehydration occurs in $\mathrm{CsH}_{2} \mathrm{PO}_{4}$ also. ${ }^{19,22}$ The danger of such an argument is immediately obvious. There are innumerable cases in which compounds with similar stoichiometries exhibit dramatically different phase transition behaviors. A notable example is the influence of deuteration on low temperature ferroelectric transitions in several $\mathrm{M}_{3} \mathrm{H}_{\left(\mathrm{XO}_{4}\right)_{2}}$ compounds: while $\mathrm{Rb}_{3} \mathrm{H}\left(\mathrm{SO}_{4}\right)_{2}, \mathrm{Rb}_{3} \mathrm{H}\left(\mathrm{SeO}_{4}\right)_{2}$, and $\mathrm{K}_{3} \mathrm{H}\left(\mathrm{SO}_{4}\right)_{2}$ do not exhibit ferroelectric transitions to temperatures as low as liquid helium, the deuterated analogs do, despite the isomorphous structures of the protonated and deuterated compounds. ${ }^{34}$

In parallel to the studies dismissing a superprotonic transition in $\mathrm{CsH}_{2} \mathrm{PO}_{4}$, several recent papers have appearing supporting its existence. Luspin et al. showed a sharp change in the elastic constants of single crystal $\mathrm{CsH}_{2} \mathrm{PO}_{4}$ to occur at $233{ }^{\circ} \mathrm{C}$, with reliable data being obtained to a temperature of $255^{\circ} \mathrm{C}^{20}$ In 2003 Boysen et al. published a definitive set of studies showing the sensitivity of the thermal behavior of $\mathrm{CsH}_{2} \mathrm{PO}_{4}$ to particle size and heating rate when examined under dry nitrogen. ${ }^{26}$ From the simultaneous measurement of thermal events and weight loss, combined with evolved gas analysis, a clear transition at $228 \pm 2{ }^{\circ} \mathrm{C}$, prior to any decomposition, was detected for all sets of experimental conditions. Furthermore, it was shown that, as would be expected, dehydration in large single crystal samples was significantly suppressed, such that a high temperature isotropic phase could be
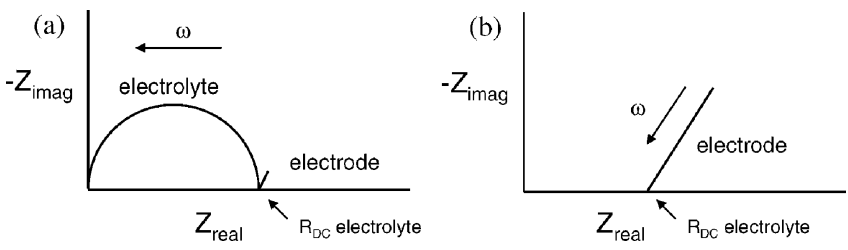

Fig. 1 Schematic impedance spectra resulting from electrode $\mid$ electrolyte $\mid$ electrode systems (a) at low temperatures and (b) at high temperatures. 
easily observed optically under cross-polarizers. The decomposition could also be suppressed by the application of high hydrostatic pressure (1 GPa). Under these conditions a transition at $260{ }^{\circ} \mathrm{C}$ was observed and the high temperature phase found to be stable to temperatures as high as $375^{\circ} \mathrm{C}$.

Almost simultaneous with the publication of these results, Otomo et al. showed that water partial pressure could be used to suppress dehydration and by this method also provided convincing conductivity measurements of the superprotonic phase. ${ }^{25}$ The raw impedance data collected both by Boysen et al. ${ }^{26}$ and Otomo et al..$^{25}$ exhibit the features described in Fig. 1, supporting the hypothesis that the analysis procedure employed by Park ${ }^{29}$ was not applicable to the high temperature phase. In a later study, Otomo et al. further showed that a water partial pressure of $0.3 \mathrm{~atm}$ was sufficient to suppress dehydration at $250{ }^{\circ} \mathrm{C}$, and that the dehydration was, in fact, reversible, with slightly decomposed samples recovering their high conductivity upon exposure to sufficient humidity. ${ }^{31}$ A preliminary evaluation of the complete $\mathrm{CsH}_{2} \mathrm{PO}_{4}-\mathrm{H}_{2} \mathrm{O}$ $\mathrm{CsPO}_{3}$ phase diagram was reported in 2004 by Boysen et al., which supported the assertion that only slight levels of humidification are necessary to suppress dehydration. ${ }^{28}$ Independently, Yamada et al. examined the structural properties of $\mathrm{CsH}_{2} \mathrm{PO}_{4}$ in 2004. ${ }^{30}$ A high temperature diffraction pattern clearly corresponding to that reported earlier by Bronowska was obtained by sealing the powdered sample to prevent dehydration. In 2005 Baranov reproduced his earlier conductivity measurements of $\mathrm{CsH}_{2} \mathrm{PO}_{4}$ and also examined the influence of ammonium substitution on the transition behavior. ${ }^{32}$ In addition to these fundamental studies of the properties of $\mathrm{CsH}_{2} \mathrm{PO}_{4}$, both Boysen et al. ${ }^{28}$ and Otomo et al. ${ }^{31}$ have shown that this material can be employed as the electrolyte in fuel cells with good long-term stability, behavior that would not be possible if the high conductivity were a transient artifact of dehydration.

In the cases where experimental procedures have been described in detail, it is apparent that weight loss and dehydration occur when $\mathrm{CsH}_{2} \mathrm{PO}_{4}$ is used in the form of loose powders, whereas single crystals typically show the strongest evidence of polymorphic phase transitions. On the basis of the thermodynamic measurements of the decomposition behavior of $\mathrm{CsH}_{2} \mathrm{PO}_{4}$, Fig. $2,{ }^{28}$ it is apparent that at the transition temperature of $230{ }^{\circ} \mathrm{C}$, a water partial pressure of only $\sim 0.026$ atm, equivalent to $100 \%$ humidity at $22{ }^{\circ} \mathrm{C}$, is sufficient to suppress dehydration. Because this value is close to ambient levels of humidity, without explicit control of water partial pressure, measured results will vary substantially depending on the laboratory climate. Furthermore, even gas flow rates, in addition to particle/crystallite size, can be expected to have a strong impact on dehydration kinetics. Thus, it is essential to explicitly control water partial pressure in any meaningful evaluation of the high temperature properties of $\mathrm{CsH}_{2} \mathrm{PO}_{4}$.

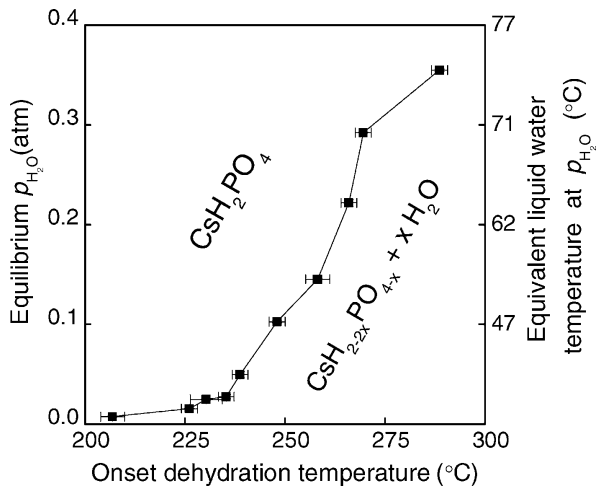

Fig. 2 Equilibrium phase diagram for the decomposition of $\mathrm{CsH}_{2} \mathrm{PO}_{4}$. Reproduced with permission from ref. 28. 

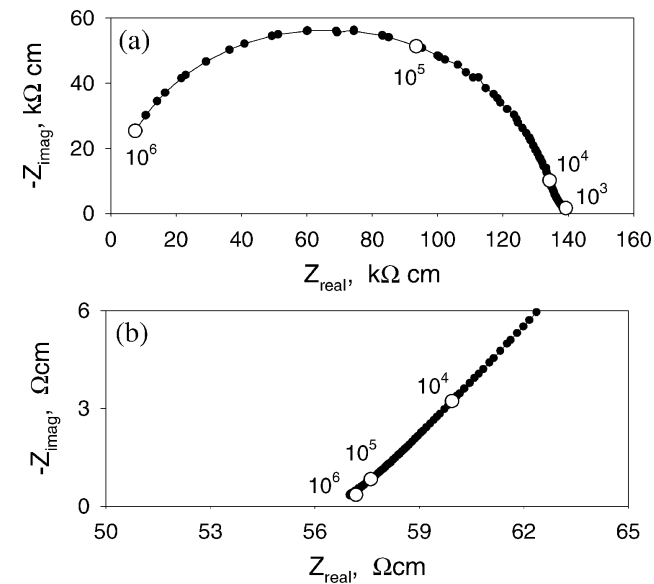

Fig. 3 Impedance spectra obtained from $\mathrm{Ag}\left|\mathrm{CsH}_{2} \mathrm{PO}_{4}\right| \mathrm{Ag}$ under humidified air $\left(\mathrm{p}\left[\mathrm{H}_{2} \mathrm{O}\right]=\right.$ $0.4 \mathrm{~atm}$ ) at (a) $220{ }^{\circ} \mathrm{C}$ and (b) $236{ }^{\circ} \mathrm{C}$, showing the dramatic change in impedance properties upon passing through the superprotonic transition at $230{ }^{\circ} \mathrm{C}$. Frequency values specified for selected data points.

\section{Conductivity of $\mathrm{CsH}_{2} \mathrm{PO}_{4}$}

While there is now an overwhelming body of evidence supporting the conclusion that $\mathrm{CsH}_{2} \mathrm{PO}_{4}$ undergoes a true, polymorphic transition to a cubic, superprotonic phase at $\sim 230{ }^{\circ} \mathrm{C}$, we deemed it important here to provide additional conductivity data under ambient pressure conditions with controlled humidity levels. To date, such data have been reported only by Otomo et al., ${ }^{31}$ with all other experiments having been carried out without explicit control of humidity.

Powders of $\mathrm{CsH}_{2} \mathrm{PO}_{4}$ were prepared from aqueous solutions of the starting reagents $\mathrm{Cs}_{2} \mathrm{CO}_{3}$ (Alfa Aesar, 99.9\%) and $\mathrm{H}_{3} \mathrm{PO}_{4}$ (ACS, $85 \% \mathrm{w} / \mathrm{w}$ aqueous solution) combined in a molar ratio of $1: 2$, to which methanol was added to induce rapid precipitation. After confirmation by X-ray powder diffraction that the desired material had been obtained, the powder was dried at $\sim 205{ }^{\circ} \mathrm{C}$ for several hours to remove surface adsorbed water so as to minimize its influence on transport properties. After drying, polycrystalline pellets of $\mathrm{CsH}_{2} \mathrm{PO}_{4}, 5.1 \mathrm{~mm}$ in diameter and $\sim 2 \mathrm{~mm}$ in thickness, were prepared by cold uniaxial pressing at $630 \mathrm{kpsi}$. Final densities were $95 \pm 2 \%$ of theoretical. Colloidal silver paste (Ted Pella 16032) was applied to either side of the samples to serve as electrodes for electrical characterization. AC impedance measurements were performed over the frequency range $20 \mathrm{~Hz}$ to $1 \mathrm{MHz}$, with an applied voltage amplitude of $1.0 \mathrm{~V}$ using an HP 4284A precision LCR (inductance-capacitance-resistance) meter. Data were collected over the temperature range of $\sim 170-255^{\circ} \mathrm{C}$, with the sample chamber maintained at $p\left(\mathrm{H}_{2} \mathrm{O}\right)=0.4 \mathrm{~atm}$ in air by passing the inlet gas (flow rate of $\sim 5 \mathrm{sccm}$ ) through water held at $75 \pm 1{ }^{\circ} \mathrm{C}$. This level of humidification ensures that decomposition is suppressed, Fig. 2. Impedance spectra were analyzed using the commercially available software package, ZView (Scribner \& Assoc.).

Typical impedance spectra obtained from these measurements are presented in Fig. 3 in Nyquist form $\left(Z_{\text {real }} v s\right.$. $-Z_{\text {imag }}$ as parametric functions of frequency, $\left.\omega\right)$ for measurements both below (at $220{ }^{\circ} \mathrm{C}$ ) and above $\left(\right.$ at $236{ }^{\circ} \mathrm{C}$ ) the transition at $230{ }^{\circ} \mathrm{C}$. Below $230{ }^{\circ} \mathrm{C}$, the spectra exhibit a single arc that extends (almost) to the origin and the low frequency intercept of this arc with the real axis corresponds to the $\mathrm{dc}$ conductivity of the electrolyte. Above $230{ }^{\circ} \mathrm{C}$, the behavior of the electrolyte can no longer be directly accessed. In this case, the (extrapolated) high frequency intercept with the real axis corresponds to the dc conductivity of the electrolyte. Quantitatively, the low temperature behavior is modeled using an equivalent circuit 
comprised of a resistor, $\mathrm{R}$, with impedance $Z_{\mathrm{R}}(\omega)=R$, and a constant phase element, Q, with impedance $Z_{\mathrm{Q}}(\omega)=\left[Y(j \omega)^{n}\right]^{-1}$, where $j=\sqrt{ }-1$, and $Y$ and $n$ are constants, placed in parallel with one another, whereas the high temperature behavior is represented by a resistor and constant phase element placed in series. That AC impedance data acquired from electrolyte materials require treatment in this manner is well-understood within the solid state ionics community, but is less widely appreciated amongst researchers in other fields.

The conductivity of $\mathrm{CsH}_{2} \mathrm{PO}_{4}$ so derived is presented in Fig. 4 in Arrhenius form for two heating and cooling cycles. This is a typical dataset, with many samples having been examined. Several features of the conductivity of $\mathrm{CsH}_{2} \mathrm{PO}_{4}$ are noteworthy. Most significant is the unambiguous existence of a high temperature phase, stable from the transition temperature of $230{ }^{\circ} \mathrm{C}$ to the highest measurement temperature of $254{ }^{\circ} \mathrm{C}$. The conductivity rises from $8.5 \times 10^{-6}$ at $223{ }^{\circ} \mathrm{C}$ to $1.8 \times$ $10^{-2} \Omega^{-1} \mathrm{~cm}^{-1}$ at $233^{\circ} \mathrm{C}$, in good agreement with the earlier work of Baranov et al. ${ }^{5}$ Moreover, within the high conductivity regime, the activation energy for charge transport is $0.418 \pm 0.002 \mathrm{eV}$, a value that is again consistent with the results of Baranov et al. This low activation energy, combined with the overall high conductivity of $\mathrm{CsH}_{2} \mathrm{PO}_{4}$ above the transition warrant the identification of the high temperature phase as superprotonic. It is fair at this stage to conclude that the literature controversy regarding the high temperature behavior of $\mathrm{CsH}_{2} \mathrm{PO}_{4}$ has been put to rest.

Another important feature of the data in Fig. 4 is the rather large difference between the conductivity of $\mathrm{CsH}_{2} \mathrm{PO}_{4}$ measured in the first heating cycle and all other examinations of the low temperature phase. We attribute the high initial conductivity to residual surface water present in the grain boundary regions of the polycrystalline material. It has been shown elsewhere that even under dry conditions, removal of this water requires several days of exposure to temperatures of $205^{\circ} \mathrm{C}$ and higher. ${ }^{26}$ The conductivity results also reveal that there is tremendous hysteresis in the superprotonic transition behavior, with the reverse transformation occurring only after the material is undercooled by almost $30{ }^{\circ} \mathrm{C}$ relative to the transition temperature on heating. This behavior likely reflects the dramatic structural differences between the low and high temperature phases, as discussed in some detail below.

\section{$\mathrm{CsH}_{2} \mathrm{PO}_{4}$ as a fuel cell electrolyte}

The viability of $\mathrm{CsH}_{2} \mathrm{PO}_{4}$ based fuel cells was first demonstrated by the authors in $2004,{ }^{28}$ and later confirmed by Otomo et al. in $2005 .{ }^{35}$ The most recent work from

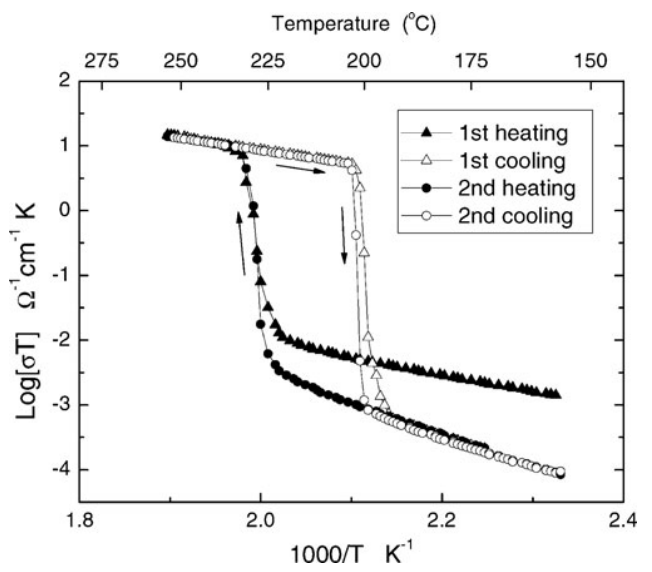

Fig. 4 Conductivity of polycrystalline $\mathrm{CsH}_{2} \mathrm{PO}_{4}$ under humidified air $\left(\mathrm{p}\left[\mathrm{H}_{2} \mathrm{O}\right]=0.4 \mathrm{~atm}\right)$ for two heating and cooling cycles. 

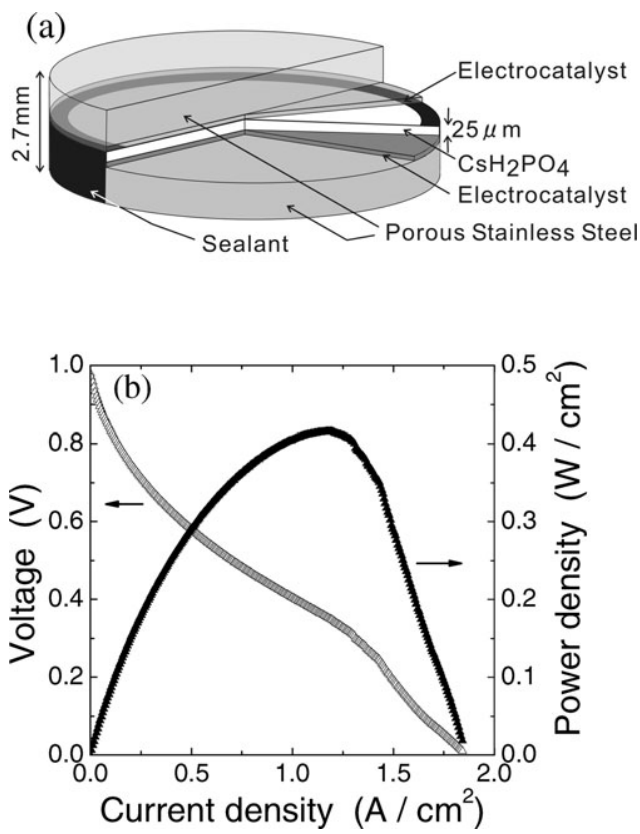

Fig. 5 (a) Schematic of thin-film fuel cell and (b) resulting polarization and power density curves for operation under humidified $\left(p\left[\mathrm{H}_{2} \mathrm{O}\right]=0.3 \mathrm{~atm}\right) \mathrm{H}_{2} / \mathrm{O}_{2}$ at $240{ }^{\circ} \mathrm{C} .{ }^{36}$ A peak power density of $415 \mathrm{~mW} \mathrm{~cm}{ }^{-2}$ was obtained. Reproduced with permission from ref. 36 .

the authors' laboratory indicates that supported electrolyte structures with membranes as thin as $25 \mu \mathrm{m}$ can be fabricated and operated, Fig. 5, yielding single cell power densities of $415 \mathrm{~mW} \mathrm{~cm}{ }^{-2}$ at peak power, ${ }^{36}$ such performance is competitive with commercially available phosphoric acid fuel cells. These data were acquired from a cell operated at $240{ }^{\circ} \mathrm{C}$ with humidified hydrogen and humidified oxygen $\left[p\left(\mathrm{H}_{2} \mathrm{O}\right)=0.3 \mathrm{~atm}\right]$ supplied to the anode and cathode, respectively. The electrodes were comprised of a composite mixture of $\mathrm{CsH}_{2} \mathrm{PO}_{4}$, Pt black and Pt supported on carbon, with a Pt loading of $7.7 \mathrm{mg} \mathrm{cm}^{-2}$ per electrode. The entire membraneelectrode-assembly was supported on a porous, stainless steel, gas-diffusion electrode, and from the absence of any influence of the gas flow rates on the polarization curves, it was demonstrated that mass transport through the support structure was not rate-limiting. The anomalous drop in voltage at high current densities (above $\sim 1.33 \mathrm{~A} \mathrm{~cm}^{-2}$ ) is due to irreversible mechanical degradation of the very thin electrolyte rather than any characteristics of the electrochemical reactions.

It is illustrative to consider the sources of overpotential in the fuel cell of Fig. 5. At $240{ }^{\circ} \mathrm{C}$ the conductivity (Fig. 4) is $2.2 \times 10^{-2} \Omega^{-1} \mathrm{~cm}^{-1}$ and thus for a membrane $25 \mu \mathrm{m}$ in thickness the electrolyte area specific resistance is $0.11 \Omega \mathrm{cm}^{2}$. Subtracting this contribution from the raw polarization curve yields the electrolyte corrected curve of Fig. 6. It is immediately evident that the membrane contributions to the polarization losses (only $\sim 11 \mathrm{mV}$ at a current density of $100 \mathrm{~mA} \mathrm{~cm}^{-2}$ ) are much smaller than those of other sources $(\sim 130 \mathrm{mV}$ at this same current density), which presumably represent slow electrocatalysis rates at the electrodes. The polarization measurements reported by Otomo et al. ${ }^{35}$ suggest even greater electrode over-

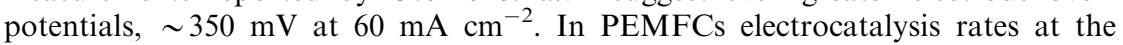
cathode are far slower than at the anode, and one might anticipate the same in the case of solid acid fuel cells, but such behavior is not an automatic characteristic of any fuel cell system. Accordingly, electrochemical experiments were performed to identify the source of electrocatalysis losses. 


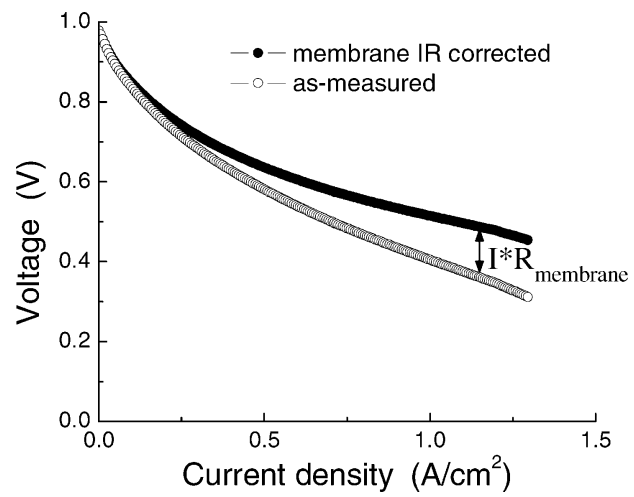

Fig. 6 Comparison between as-measured and membrane resistance (IR) corrected polarization curves for the fuel cell shown in Fig. 5.

For the examination of electrochemical characteristics of $\mathrm{CsH}_{2} \mathrm{PO}_{4}$ based fuel cells, a $700 \mu \mathrm{m}$ thick cell configured with three electrodes was prepared, Fig. 7. As in the fuel cell measurements, the electrodes consisted of a composite of $\mathrm{CsH}_{2} \mathrm{PO}_{4}, \mathrm{Pt}$ black and Pt supported on carbon, added in a $3: 3: 1$ weight ratio. Naphthalene, incorporated into the electrode composite as a fugitive pore-former, was removed under argon at a temperature of $\sim 200{ }^{\circ} \mathrm{C}$ prior to data collection. Both $\mathrm{AC}$ impedance spectroscopy and galvanostatic current interrupt (GCI) methods were used to characterize electrochemical behavior. Measurements were performed with the cell exposed to a uniform atmosphere of either humidified hydrogen or humidified oxygen $\left[p\left(\mathrm{H}_{2} \mathrm{O}\right)=0.57 \mathrm{~atm}\right.$, gas flow rate $\left.=30 \mathrm{sscm}\right]$ and held at a temperature of $238^{\circ} \mathrm{C}$. Impedance spectroscopy was carried out in the galvanostatic mode using a current amplitude of $2 \mathrm{~mA}$, and a frequency range of $30 \mathrm{mHz}$ to $5 \mathrm{kHz}$. With this frequency range (extending to lower values than in Fig. 3) it was possible to observe the low frequency intercept with the real axis in the Nyquist representation, and thereby determine the resistance due to the electrodes. Measurements were performed under an applied current bias of $0-28 \mathrm{~mA} \mathrm{~cm}{ }^{-2}$. The GCI data were collected using initial current values of $2-100 \mathrm{~mA}$ (corresponding to current densities of $1.1-113 \mathrm{~mA} \mathrm{~cm}^{-2}$ ). The resulting voltage decay curves were fit to an appropriate exponential decay function to establish the proportion of the voltage due to capacitive (electrode) behavior for each value of initial current.

Examples of the impedance spectra and current decay curves obtained for cells exposed to humidified hydrogen and to humidified oxygen are presented in Fig. 8 and 9, respectively. Similar to the behavior of PEM fuel cells, hydrogen electrooxidation proceeds far more rapidly than oxygen electroreduction. The GCI curve (Fig. 8b) suggests that at a current density of $\sim 115 \mathrm{~mA} \mathrm{~cm}^{-2}$, the hydrogen electrode is responsible for only $\sim 0.3 \mathrm{mV}$ out of the $\sim 150 \mathrm{mV}$ of overpotential associated with the electrodes (Fig. 6). Similarly, the impedance spectra indicate that the area specific anode polarization resistance is only $\sim 0.06 \Omega \mathrm{cm}^{2}$ (under zero bias).

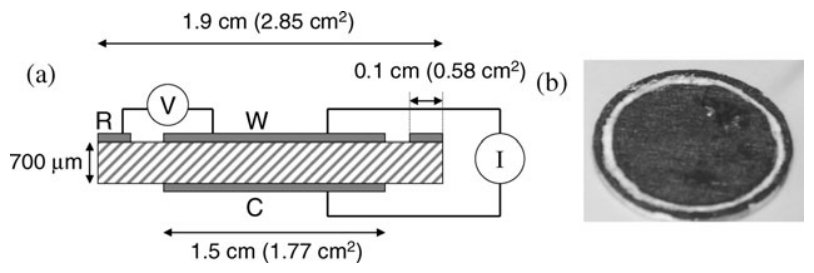

Fig. 7 Configuration for three-point electrical measurement (a) schematic and (b) photo of cell showing working and reference electrodes. 

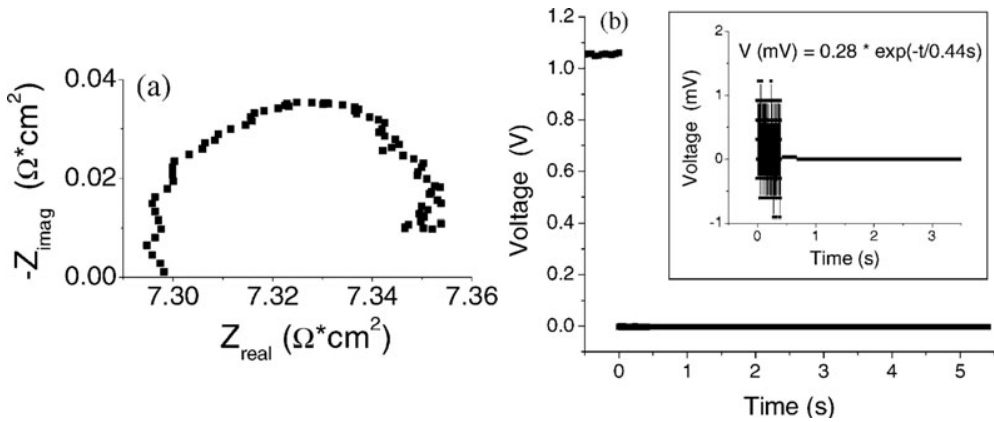

Fig. 8 Electrochemical characteristics of $\mathrm{Pt}-\mathrm{C}\left|\mathrm{CsH}_{2} \mathrm{PO}_{4}\right| \mathrm{Pt}-\mathrm{C}$ cells under humidified hydrogen $\left(p\left[\mathrm{H}_{2} \mathrm{O}\right]=0.4 \mathrm{~atm}\right)$; (a) AC impedance spectrum, and (b) voltage decay curve after application of $113 \mathrm{~mA} \mathrm{~cm}^{-2}$ current. Inset shows short time data and fit to exponential decay.

In contrast, the GCI data indicate that the cathode overpotential is close to $80 \mathrm{mV}$ at just $56.5 \mathrm{~mA} \mathrm{~cm}^{-2}$ (Fig. 9b), whereas under zero bias the area specific cathode polarization resistance, according to the impedance results, is $\sim 9.5 \Omega \mathrm{cm}^{2}$. In addition, both the voltage decay curves and impedance spectra suggest a two-step reaction process for oxygen electroreduction, with each step exhibiting a measurably different time constant.

From the GCI data collected under oxygen, the cathodic overpotential curve, $\eta_{\mathrm{C}}$, was generated, Fig. 10. From a fit to a modified form of the Tafel equation, we obtain an exchange current density of $5.4 \pm 0.4 \mathrm{~mA} \mathrm{~cm}^{-2}$, which is about a factor of twenty lower than what has been reported for PEMFCs. ${ }^{37}$ The $\eta_{\mathrm{C}}$ values determined in this manner correspond reasonably well to the total electrode overpotential curve obtained from the fuel cell measurements, while the slope of the overpotential curve at zero current density $\left(6.2 \Omega \mathrm{cm}^{2}\right)$ is acceptably similar to the zero-bias area-specific polarization resistance measured by impedance spectroscopy $\left(9.5 \Omega \mathrm{cm}^{2}\right)$, particularly given that different samples were used in each of the three experiments. In total, the results indicate that all sources of potential drop have been accounted for and further show that, although quantitative interpretation may not yet be possible, the cathode is clearly the rate-limiting step in state-of-the-art solid acid fuel cells. Increasing fuel cell power output will thus require enhancements in the oxygen electroreduction rates rather than further decreases in electrolyte thickness.

The 'warm' temperature of operation of $\mathrm{CsH}_{2} \mathrm{PO}_{4}$ based fuel cells opens up possibilities for the direct utilization of fuel cells other than hydrogen. In particular, at $250{ }^{\circ} \mathrm{C}$ one expects that methanol steam reforming will proceed rapidly and therefore that such fuel cells can be operated on methanol-water mixtures. In

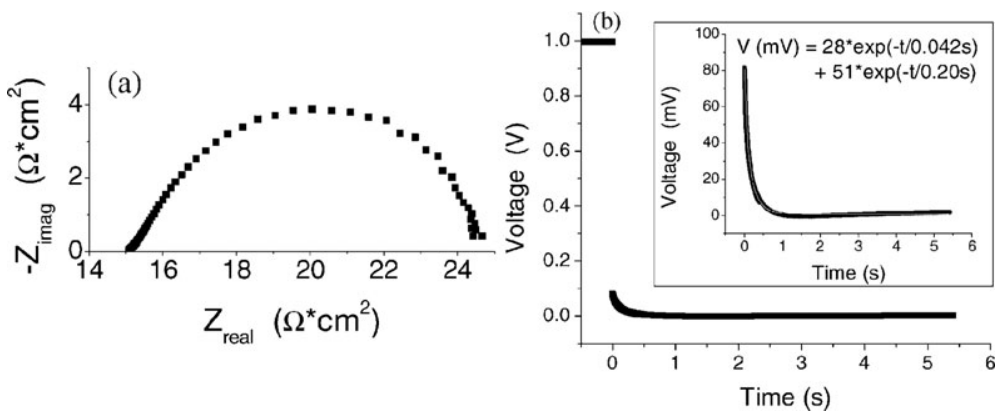

Fig. 9 Electrochemical characteristics of $\mathrm{Pt}-\mathrm{C}\left|\mathrm{CsH}_{2} \mathrm{PO}_{4}\right| \mathrm{Pt}-\mathrm{C}$ cells under humidified oxygen $\left(p\left[\mathrm{H}_{2} \mathrm{O}\right]=0.4 \mathrm{~atm}\right)$; (a) AC impedance spectrum, and (b) voltage decay curve after application of $56.5 \mathrm{~mA} \mathrm{~cm}^{-2}$ current. Inset shows short time data and fit to exponential decay. 


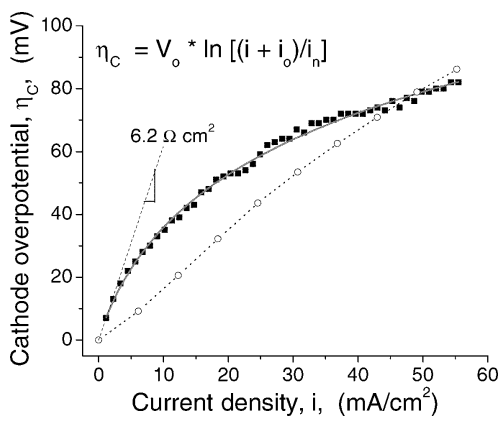

Fig. 10 Comparison between the cathodic overpotential for oxygen electroreduction over $\mathrm{Pt}-\mathrm{C}$ on $\mathrm{CsH}_{2} \mathrm{PO}_{4}$ determined by GCI methods (closed squares) with the total electrode overpotential determined from complete fuel cell measurements (open circles) at a temperature $240{ }^{\circ} \mathrm{C}$ and a water partial pressure of 0.4-0.6 atm. The solid line indicates the best fit to the GCI data according to the equation shown in the figure, where $i_{o}$ is the exchange current density.

addition, the tolerance of the anode electrocatalyst to fuel stream poisons such as $\mathrm{CO}$ are expected to be high. It can further be expected that the solid nature of the electrolyte will ensure zero fuel crossover and thereby enable the use of high concentrations of alcohol in the fuel stream. With these considerations in mind, the authors recently demonstrated methanol and ethanol fuel cells with rather remarkable power densities, Fig. $11{ }^{38}$ These cells, in which $\mathrm{Pt}-\mathrm{Ru}$ served as the electrooxidation catalyst (rather than simple $\mathrm{Pt}$ ) and the membrane was $47 \mu \mathrm{m}$ in thickness, were constructed with a steam reforming catalyst $\left(\mathrm{Cu}-\mathrm{ZnO} / \mathrm{Al}_{2} \mathrm{O}_{3}{ }^{39}\right)$ placed directly adjacent to the anode. In order to permit these direct comparisons of behavior under different fuels, the methanol and ethanol were supplied to the anode at rates equivalent to that at which hydrogen was supplied, assuming complete alcohol reformation. Quite notably, the open circuit potential under methanol (43 vol\%) is as high as it is under hydrogen, while the peak power output under methanol is reduced only by $15 \%$ relative to that under hydrogen. The behavior is in stark contrast to polymer based fuel cells, in which direct operation on methanol produces power outputs that are only about $15 \%$ of what can be obtained from hydrogen. Furthermore, our analysis indicates that the major limitation in the $\mathrm{CsH}_{2} \mathrm{PO}_{4}$ based methanol fuel cell is the rate at which methanol reforming occurs over the $\mathrm{Cu}-\mathrm{ZnO} / \mathrm{Al}_{2} \mathrm{O}_{3}$ catalyst rather than poisoning of the anode electrocatalyst by $\mathrm{CO}$.

Thus, the fuel cell experiments performed to date point out the potentially fruitful avenues for technological developments. As with all technological endeavors, basic

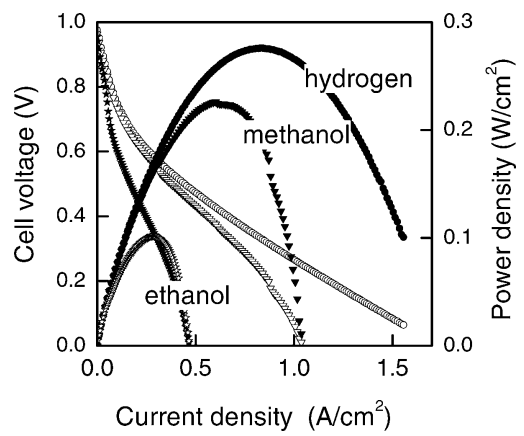

Fig. 11 Polarization and power density curves at $240{ }^{\circ} \mathrm{C}$ for fuel cells in which a steam reforming catalyst was placed directly adjacent to the fuel cell anode. Humidified oxygen was supplied to the anode and the fuel indicated (humidified) was supplied to the anode. Reproduced with permission from ref. 38 
scientific studies of physical phenomena are expected to provide the insight required for further advances. With this philosophy in mind, we now turn to an analysis of the fundamental driving force for the superprotonic transition in $\mathrm{CsH}_{2} \mathrm{PO}_{4}$.

\section{Configurational entropy of superprotonic $\mathrm{CsH}_{2} \mathrm{PO}_{4}$}

In a recent study of $\mathrm{CsHSO}_{4}$, we proposed a methodology for evaluating the configurational entropy of phases in which both global hydrogen bond disorder and local oxyanion group disorder occur and are independent of one another. ${ }^{40} \mathrm{It}$ was found that the measured transition entropy (determined from thermal analysis) could be explained by applying this methodology to the superprotonic structure of $\mathrm{CsHSO}_{4}$ as proposed by Jirak et al. ${ }^{41}$ The suitability of that approach for the evaluation of the configurational entropy of $\mathrm{CsH}_{2} \mathrm{PO}_{4}$ is now considered here. Doing so requires not only an analysis of the configurational entropy of superprotonic $\mathrm{CsH}_{2} \mathrm{PO}_{4}$ by this method, but also knowledge of the (experimental) transition entropy and the configurational entropy of the room temperature structure.

\section{Experimental studies of the transition enthalpy and entropy}

A review of the literature indicates that several values for the transition enthalpy have been reported, Table 2 . The early reports of Metcalfe and Clark ${ }^{11}$ and of Gupta et al. ${ }^{13}$ suggested a transition enthalpy of $\sim 8 \mathrm{~kJ} \mathrm{~mol}^{-1}$, whereas later studies, which presumably utilized modern instrumentation, consistently indicate a transition enthalpy of $11.6 \mathrm{~kJ} \mathrm{~mol}^{-1}$. Accordingly, this higher value is taken to be the physically correct value, implying a transition entropy $\left(\Delta S=\Delta H / T_{\mathrm{C}}\right)$ of $23 \pm$ $1 \mathrm{~J} \mathrm{~mol}^{-1} \mathrm{~K}^{-1}$ for a transition temperature of $230{ }^{\circ} \mathrm{C}$. For consistency, this single value of the transition temperature has been used for the conversion rather than the slightly differing transition temperatures reported in those studies.

\section{Room temperature structure}

At room temperature $\mathrm{CsH}_{2} \mathrm{PO}_{4}$ adopts a monoclinic structure, in which $\mathrm{PO}_{4}$ groups are linked together by both asymmetric, single-minimum hydrogen bonds and symmetric, double-mimina bonds. These bonds, formed between oxygen atoms of neighboring phosphate groups, generate corrugated two-dimensional $\left[\mathrm{H}_{2} \mathrm{PO}_{4}{ }^{=}\right]_{\infty}$ layers, in between which are located the Cs atoms, Fig. 12. The space group in the standard, primitive setting is $P 2_{1} / m[a=7.912(2), b=6.383(1), c=4.8802(8) \AA$ and $\left.\beta=107.73(2)^{\circ}\right] \cdot{ }^{43}$ Instead of this choice $\mathrm{CsH}_{2} \mathrm{PO}_{4}$ is often described in the nonprimitive $B 2_{1} / \mathrm{m}$ setting because doing so reveals the pseudo-orthorhombic symmetry of the structure $[a=4.8725(1), b=6.3689(1), c=15.0499(8) \AA$ and $\beta=$ $\left.90.22(1)^{\circ}\right] .{ }^{44}$ The asymmetric unit contains one $\mathrm{Cs}$ atom, one $\mathrm{P}$ atom, three $\mathrm{O}$ atoms and two $\mathrm{H}$ atoms. Using the atom assignments of Nelmes and Choudhary ${ }^{44}$ the asymmetric hydrogen bond has configuration $\mathrm{O}(1)-\mathrm{H}(1) \cdots \mathrm{O}(2)$, whereas the symmetric bond has configuration $\mathrm{O}(1) \ldots \mathrm{H}(2)-\mathrm{H}(2) \ldots(\mathrm{O} 1)$, with the $\mathrm{H}(2)$ atoms displaying an average site occupancy of 0.5 . On cooling, $\mathrm{CsH}_{2} \mathrm{PO}_{4}$ undergoes a

Table 2 Reported values of the enthalpy and temperature of the superprotonic transition in $\mathrm{CsH}_{2} \mathrm{PO}_{4}$

\begin{tabular}{lll}
\hline$\Delta H / \mathrm{kJ} \mathrm{mol}^{-1}$ & $T_{\mathrm{c}} /{ }^{\circ} \mathrm{C}$ & Source \\
\hline 7.6 & 230 & Metcalf $(1978)^{11}$ \\
$8.4 \pm 0.8$ & 235 & Gupta $(1980)^{13}$ \\
$11.3 \pm 0.5$ & $230 \pm 2$ & Chisholm $(2002)^{42}$ \\
$11.3 \pm 0.6$ & $228 \pm 2$ & Boysen $(2003)^{26}$ \\
$11.9 \pm 0.3$ & 229 & Yamada $(2004)^{30}$ \\
\hline
\end{tabular}




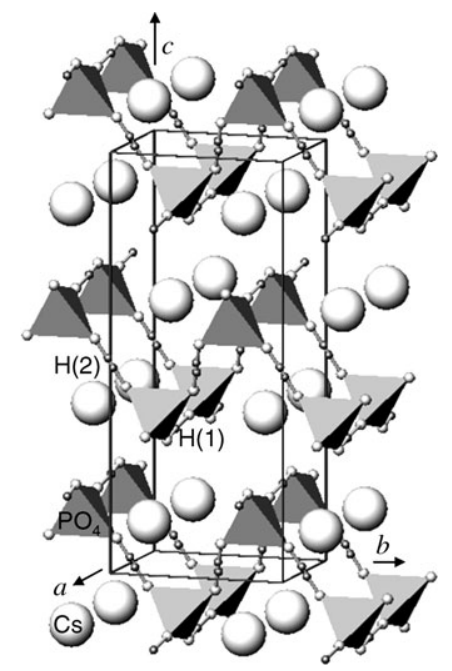

Fig. 12 Crystal structure of $\mathrm{CsH}_{2} \mathrm{PO}_{4}$ in its room temperature, paraelectric form, taken in space group setting $B 2_{1} / \mathrm{m}^{44}$ The disordered hydrogen bonds formed by the $\mathrm{H}(2)$ atoms create a 1-dimensional chain of phosphate groups along [010], in turn, linked by the ordered hydrogen bonds formed by $\mathrm{H}(1)$ to generate a layered structure.

ferroelectric transition to a monoclinic structure of space group $P 2_{1}$, at which the inversion symmetry about the $\mathrm{O}(1)-\mathrm{O}(1)$ hydrogen bond is removed and the bond becomes asymmetric (with a single minimum).

The molar configurational entropy that one would expect to result from the disordered hydrogen bond in $\mathrm{CsH}_{2} \mathrm{PO}_{4}$ is $R \ln (2)=5.76 \mathrm{~J} \mathrm{~mol}^{-1} \mathrm{~K}^{-1}$. On the basis of calorimetric measurements of $\mathrm{CsH}_{2} \mathrm{PO}_{4}$ cooled through the ferroelectric transition, however, Imai has suggested an entropy difference of only $3.2 \pm 0.2 \mathrm{~J} \mathrm{~mol}^{-1}$ $\mathrm{K}^{-1}$ between the paraelectric and ferroelectric phases, ${ }^{45}$ whereas Kanda et al. reported an even lower value of $1.05 \pm 0.2 \mathrm{~J} \mathrm{~mol}^{-1} \mathrm{~K}^{-1}$. ${ }^{56}$ This apparent paradox may be the result of correlations between $\mathrm{O}(1)-\mathrm{O}(1)$ hydrogen bonds at temperatures above the ferroelectric transition. Such correlations give rise to dynamic domains in which structural characteristics of the ferroelectric phase are retained at elevated temperatures, with the mean domain size decreasing with increasing temperature. As a consequence, the thermal signature of the ferroelectric phase transition may be spread out over a wide temperature regime and result in an artificially depressed value of the enthalpy (and hence entropy) of the transition. Although both sets of authors have attempted to explicitly account for these effects, the significant discrepancy between the reported values suggests that accurate treatment of the problem presents significant experimental and theoretical challenges. In particular, it appears that underestimation of the transition entropy occurs because too much of the thermal signal can be easily attributed to vibrational heat capacity and to experimental background. ${ }^{45}$ In light of these challenges, we choose here to assign the full expected value of $5.76 \mathrm{~J} \mathrm{~mol}^{-1} \mathrm{~K}^{-1}$ to the configurational entropy of $\mathrm{CsH}_{2} \mathrm{PO}_{4}$ in the room temperature, paraelectric phase.

\section{High temperature structure}

The high temperature structure of $\mathrm{CsH}_{2} \mathrm{PO}_{4}$ is shown in Fig. 13. The compound adopts a CsCl-like structure with space group $\mathrm{Pm}-3 m$ and lattice constant 4.9549(4) $\AA$ at $515 \mathrm{~K} .{ }^{30}$ The Cs atoms reside at the corners of the primitive unit cell and the $\mathrm{PO}_{4}$ group is orientationally disordered about the center, taking on one of six possible orientations. The oxygen positions are numbered so as to indicate the set of 


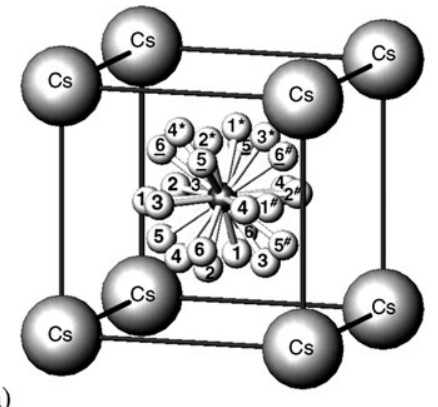

(b)

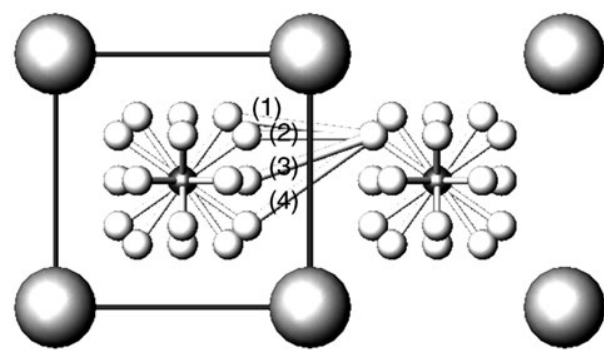

Fig. 13 High temperature structure of $\mathrm{CsH}_{2} \mathrm{PO}_{4}$; (a) single unit cell and (b) hydrogen bonds between neighboring cells. Hydrogen bonds (indicated by the numbers in parentheses) have respective lengths of $2.85,2.46,2.76$ and $3.03 \AA$. The elevations of the oxygen atoms associated with these bonds are respectively, $0.5,0.5,0.634$ and 0.5 .

four sites associated with each of the six orientations. It is noteworthy that several related compounds also adopt this structure at slightly elevated temperature, including $\mathrm{Cs}_{2}\left(\mathrm{HSO}_{4}\right)\left(\mathrm{H}_{2} \mathrm{PO}_{4}\right), \alpha-\mathrm{Cs}_{3}\left(\mathrm{HSO}_{4}\right)_{2}\left(\mathrm{H}_{2} \mathrm{PO}_{4}\right), \mathrm{Cs}_{5}\left(\mathrm{HSO}_{4}\right)_{3}\left(\mathrm{H}_{2} \mathrm{PO}_{4}\right)_{2}$ and even $\mathrm{CsH}\left(\mathrm{PO}_{3} \mathrm{H}\right) .{ }^{46}$ The orientational disorder of the oxyanion group can be understood to arise from the incompatibility of the tetrahedral unit with the octahedral symmetry at the cube center. In principle, it would be possible to orient the $\mathrm{PO}_{4}$ group such that one of the $\mathrm{P}-\mathrm{O}$ bonds were aligned with the $\langle 111\rangle$ body diagonal and retain the overall cubic symmetry of the structure (removing the octahedral symmetry from the center and lowering the overall space group symmetry to $P 432$ ). However, the distance between the phosphorous and caesium atoms along this direction is only $4.296 \AA$ and indicates that the oxygen cannot lie directly on the line between them. Placement of the oxygen atoms at sites displaced from the body diagonal (to $1 / 21 / 40.366$ ) in a manner that retains the cubic symmetry produces the structure shown in Fig. 13.

As noted by Yamada et al. ${ }^{30}$ the shortest oxygen-oxygen distance between neighboring $\mathrm{PO}_{4}$ groups is $2.46 \AA$, consistent with the length of a strong (single minimum) hydrogen bond. This bond, corresponding to bond (2) in Fig. 13b, links neighboring $\mathrm{PO}_{4}$ groups via the face of the simple cubic unit cell. Each of the oxygen atoms marked with a number sign (\#) in Fig. 13a has an oxygen neighbor in the phosphate group that resides directly to the right of the one shown with which a bond of this length could be formed. Similarly, the four oxygen atoms marked with asterisks (*) could form bonds of this length via the upper face of the cube. Several additional hydrogen bonds with somewhat longer oxygen-oxygen bond distances are also possible, which similarly provide linkages through the faces of the simple cubic unit cell. These bonds, if directed towards the phosphate group located above the one shown, involve the oxygen atoms identified with underlined labels in Fig. 13a.

\section{Configurational entropy of systems with globally disordered hydrogen bonds}

The approach we recently proposed ${ }^{40}$ for the evaluation of the configurational entropy of $\mathrm{CsHSO}_{4}$ follows the elegant model put forward by Pauling to describe the residual entropy of ice. Hexagonal ice $\left(I_{\mathrm{h}}\right)$ has a structure, shown schematically in a two-dimensional representation in Fig. 14, in which each oxygen atom is tetrahedrally coordinated by four other oxygen atoms, and between each of these is a disordered hydrogen bond. ${ }^{47}$ Pauling noted that the structure 'obeyed' several rules limiting the allowable hydrogen bond configurations, and then developed a means of calculating the number of configurations which conformed to those rules. ${ }^{48}$ These so-called ice rules are: (1) each oxygen atom has two and only two protons (no 


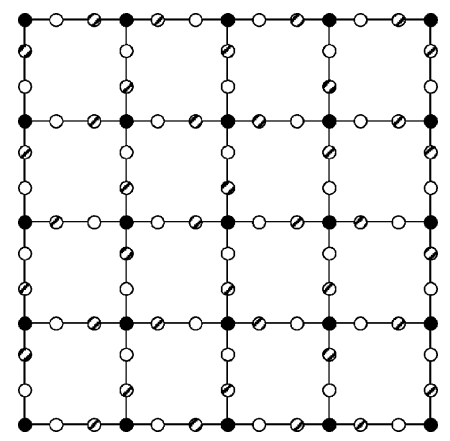

Fig. 14 Highly schematic rendition of the structure of hexagonal ice $\left(I_{\mathrm{h}}\right)$. Solid circles represent oxygen atoms, straight lines represent (double-minima) hydrogen bonds, hatched circles represent occupied proton sites and open circles represent unoccupied proton sites. Every oxygen atom has two protons as immediate neighbors so as to form water molecules, and every hydrogen bond is occupied by one and only one proton.

hydronium or hydroxyl ions are considered); (2) each hydrogen bond has one and only one proton (no L or D defects); (3) the hydrogen bonds are directed approximately towards the neighboring oxygen atoms; and (4) interaction between non-neighboring $\mathrm{H}_{2} \mathrm{O}$ molecules does not influence the distribution of hydrogen bond configurations. If one considers a particular oxygen atom, then, there are four possible locations for its first proton, and three for its second proton. Of these configurations, only one-half are unique, bringing the number of possible configurations for an isolated $\mathrm{H}_{2} \mathrm{O}$ group to $(4 !) /[(2 !)(2 !)]=6$. Within the structure of ice, one-half of all the possible hydrogen bonds are occupied, thus the probability that any particular bond is open or available for occupation by the protons of the $\mathrm{H}_{2} \mathrm{O}$ group of interest is also one-half, reducing the number of $\mathrm{H}_{2} \mathrm{O}$ group configurations by a factor of $\frac{1}{2}$ for each proton. With this final consideration the total number of possible configurations per $\mathrm{H}_{2} \mathrm{O}$ molecule, $\Omega$, is $(6)\left(\frac{1}{2}\right)\left(\frac{1}{2}\right)=6 / 4$. Formally, this result can be expressed as

$$
\Omega_{H}=\left(\begin{array}{l}
\text { \#of proton } \\
\text { configuration }
\end{array}\right)\left(\begin{array}{l}
\text { probability a proton } \\
\text { site is open }
\end{array}\right)\left(\begin{array}{l}
\text { \#of } \\
\text { protons }
\end{array}\right)
$$

The residual entropy so determined, $3.37 \mathrm{~J} \mathrm{~mol}^{-1} \mathrm{~K}^{-1}$, matches almost precisely the experimental value of $3.65 \mathrm{~J} \mathrm{~mol}^{-1} \mathrm{~K}^{-1},{ }^{49}$ and Pauling's insight resolved a major puzzle in statistical thermodynamics.

In assessing whether or not such an approach is appropriate for the evaluation of the configurational entropy of disordered oxyanion compounds, one must consider the following key question: is the orientation of the oxyanion related to the hydrogen bonds that the group forms? That is, are the $\mathrm{XO}_{4}$ orientation and the location of hydrogen bonds correlated or independent? In the case of $\mathrm{CsHSO}_{4}$, several models of the high temperature structure have been reported. In the Jirak model, ${ }^{41}$ there is only one crystallographically distinct oxygen atom, a feature that argues towards the independence of the hydrogen bond locations and the tetrahedral group orientation. Other models, however, such as those of Belushkin ${ }^{50}$ and Merinov ${ }^{51,52}$ in particular, distinguish between donor and acceptor oxygen atoms, and thus the sulfate group orientation in these structural models is fixed by the location of the hydrogen bonds. Accordingly, these structures cannot legitimately be evaluated by an extension of the Pauling approach. In the case of $\mathrm{CsH}_{2} \mathrm{PO}_{4}$, there is only one crystallographically distinct oxygen atom, ${ }^{30}$ and, like the Jirak structure for $\mathrm{CsHSO}_{4}$, this atom can serve either as donor or acceptor in the hydrogen bond. It would appear that 
superprotonic $\mathrm{CsH}_{2} \mathrm{PO}_{4}$, for which there is no structural ambiguity, would then be a straightforward phase to evaluate in terms of the extended Pauling approach. But appearances are deceptive indeed!

Consider superprotonic, tetragonal $\mathrm{CsHSO}_{4}$ according to the model proposed by Jirak. ${ }^{41}$ The structure has characteristics of the zinc blende structure, in that each sulfate group has four neighboring sulfate groups, thus there are four directions in which hydrogen bonds can be formed. In addition, each sulfate group can reside in one of two orientations, and each orientation is compatible with any distribution of hydrogen bonds. Thus, the hydrogen bond distribution and sulfate group orientation can be evaluated separately, and they contribute in a multiplicative sense to the overall number of configurations available to $\mathrm{CsHSO}_{4}$. Quantitatively, the number of hydrogen bond configurations can be treated exactly as given in eqn (1), but with the numerical values modified to reflect the specific structural characteristics of $\mathrm{CsHSO}_{4}$, which also imply a modification to the ice rules. ${ }^{40}$ Here we have (1) one and only one proton is associated with each tetrahedron; (2) one and only one proton occupies each hydrogen bond that is formed; (3) hydrogen bonds are directed towards oxygen atoms of neighboring tetrahedra; and (4) interaction between nonneighboring $\mathrm{HSO}_{4}$ tetrahedra does not influence the distribution of hydrogen bond configurations. With these modifications, we find that the number of hydrogen bond configurations available for an isolated $\mathrm{HSO}_{4}$ group is 4 !/3! (the single proton may form a bond along any of the four bond directions), the probability that a site is available or open is $\left(\frac{3}{4}\right)$, and this probability consideration must be applied to one proton. Thus, $\Omega_{\mathrm{H}}=(4)\left(\frac{3}{4}\right)^{1}$. Furthermore, as discussed above, $\Omega_{\mathrm{tetr}}=2$, giving the total number of configurations as $\Omega=\Omega_{\mathrm{H}} \Omega_{\mathrm{tetr}}=6$. The implied transition entropy, $14.90 \mathrm{~J} \mathrm{~mol}^{-1} \mathrm{~K}^{-1}$, is in excellent agreement with the measured value of $14.8 \pm$ $0.2 \mathrm{~J} \mathrm{~mol}^{-1} \mathrm{~K}^{-1}$, ${ }^{40}$ supporting the validity of this analysis under the assumption that all changes in entropy are configurational in nature.

Buried within the modified 'extended' ice rules are some rather profound implications for the proton transport behavior of $\mathrm{CsHSO}_{4}$. The first rule is equivalent to stating that there is only one donor oxygen atom per sulfate group, a physically reasonable expectation, but one that, as in the case of ice, rules out the presence of defects such as $\mathrm{SO}_{4}^{=}$and $\mathrm{H}_{2} \mathrm{SO}_{4}^{0}$ in significant enough quantities to impact the total configurational entropy. The second rule, also in analogy to ice, rules out the presence of doubly occupied hydrogen bonds or D-defects, another physically reasonable expectation. In contrast to ice, however, L-defects have no meaning because on average, $\frac{1}{2}$ of the possible hydrogen bonds are unoccupied. Moreover, in further contrast to ice, the combination of the second and fourth rules implies that any number of the non-donor oxygen atoms of the $\mathrm{HSO}_{4}$ group can serve as acceptor atoms in hydrogen bond formation. Thus, each sulfate group will form anywhere between one and four hydrogen bonds, with the sole restriction that one and only one will be formed as a result of a donor oxygen atom. A schematic illustrating the overall situation is presented in Fig. 15.

For this set of assumptions to be consistent with high conductivity in superprotonic $\mathrm{CsHSO}_{4}$, it must be a sharp increase in the mobility of protonic defects, rather than a sharp increase in the concentration of such defects, that gives rise to the dramatic increase in conductivity at the transition. In fact, such an interpretation has been recently suggested on the basis of ${ }^{1} \mathrm{H}$ NMR studies. Yoshida et al. ${ }^{53}$ observed the shape change in the ${ }^{1} \mathrm{H}$ NMR peak of single crystal $\mathrm{CsHSO}_{4}$ as it was heated through the phase transition. A sharp Lorentzian peak, assigned to mobile protons, was superimposed on a broad Gaussian peak, assigned to immobile protons. The ratio of the integrated intensities of these two peaks were followed as a function of temperature, and the Gaussian contribution was found to gradually decrease with increasing temperature. This contribution finally disappeared at $117{ }^{\circ} \mathrm{C}$, indicating that $100 \%$ of the protons are mobile a full $24{ }^{\circ} \mathrm{C}$ below the superprotonic transition.

Further insight on this point can be gained by comparison with the behavior of $\mathrm{H}_{2} \mathrm{SO}_{4}$. The electrical conductivity of anhydrous sulfuric acid at $25^{\circ} \mathrm{C}$ is $1.04 \times 10^{-2}$ 
(a)
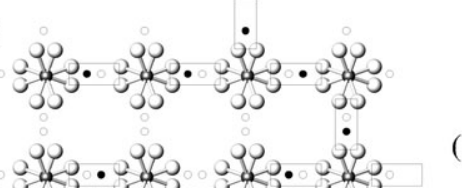

(b)
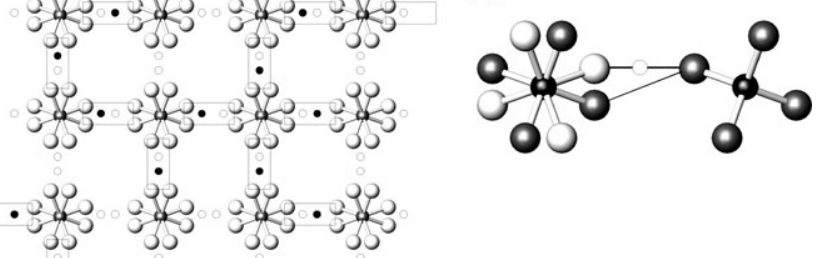

Fig. 15 Schematic rendition of the tetragonal structure of superprotonic $\mathrm{CsHSO}_{4}$. Small circles represent proton positions, with closed circles being occupied and open circles being unoccupied. Rectangles indicate hydrogen bonds that are formed, which are fewer than the number of possible hydrogen bonds. Each $\mathrm{SO}_{4}$ group resides in one of two possible orientations, and each has one and only one donor oxygen atom (i.e., the $\mathrm{HSO}_{4}$ is the basic unit). As shown in (b) either orientation of the sulfate group accommodates hydrogen bonds with neighboring sulfate groups.

$\Omega^{-1} \mathrm{~cm}^{-1},{ }^{54}$ comparable to that of superprotonic solid acids. Moreover, proton conduction is believed to occur via a mechanism similar to that operative in superprotonic $\mathrm{CsHSO}_{4}$, which has rapid sulfate group reorientation facilitating long-range proton transport. Under ambient temperatures, the autopyrolysis of $\mathrm{H}_{2} \mathrm{SO}_{4}$ results in concentrations of $\mathrm{H}_{3} \mathrm{SO}_{4}{ }^{+}$and $\mathrm{HSO}_{4}{ }^{-}$of only 0.15 and $0.11 \mathrm{~mol} \%$, respectively. ${ }^{55}$ Thus, high concentrations of such defects are not required for attaining high proton conductivity. It is also noteworthy that the energetics of ionic defect formation must surely be dominated by Coulombic interactions, which, in turn, are governed by interatomic distances. Because the overall anion-cation distances in $\mathrm{CsHSO}_{4}$ are relatively unchanged between the monoclinic (low conductivity) and tetragonal (superprotonic) phases, it is unlikely that the concentration of defects would change by an amount that could account for an increase in conductivity by four orders of magnitude upon passing through the superprotonic transition.

We now consider the situation of $\mathrm{CsH}_{2} \mathrm{PO}_{4}$. Unlike superprotonic $\mathrm{CsHSO}_{4}$, the oxyanion groups of the phosphate each have six nearest oxyanion neighbors, as implied by the $\mathrm{CsCl}$-like structure. Thus, there are six directions in which hydrogen bonds can be formed. To simplify the discussion, we replace, for the moment, the disordered $\mathrm{H}_{2} \mathrm{PO}_{4}$ group by a hypothetical $\mathrm{H}_{2} \mathrm{XO}_{6}$ oxyanion group in which the oxygen sites are fully occupied and oxygen atoms (as in the real structure) can equally well serve as donors or acceptors in hydrogen bond formation. By analogy to ice, the number of hydrogen bond configurations possible in this hypothetical compound results from the placement of two protons over six hydrogen positions, modified by the probability $(4 / 6)$ that any proton site is open or available. Thus, $\Omega_{\mathrm{H}}=(6 ! / 4 ! 2 !)(4 / 6)^{2}=20 / 3=6.67$ readily falls out of the analysis. The conceptual challenge arises when considering the configurational disorder of the tetrahedral groups to obtain the quantity $\Omega_{\text {tetr }}$.

In $\mathrm{CsHSO}_{4}$ a value of 2 is assigned to $\Omega_{\text {tetr }}$ because there are two sulfate group orientations compatible with any hydrogen bond configuration. This also coincides with the fact that there are two oxygen positions associated with the formation of any particular hydrogen bond, as indicated schematically in Fig. 15. The situation in $\mathrm{CsH}_{2} \mathrm{PO}_{4}$ differs in that there are several (depending on the distance criteria used) oxygen positions associated with any particular hydrogen bond, but this number does not coincide with the number of phosphate group orientations. Furthermore, the precise cut-off distance beyond which neighboring oxygen atoms should not be 
considered linked via a hydrogen bond is not entirely obvious. These points are clarified in the following examples.

Let the phosphate group, Fig. 13, have a hydrogen bond configuration such that one hydrogen bond extends out of the top of the cube in which the phosphate group resides and another one extends out of the bottom. Let us term this a 'straightthrough' configuration of hydrogen bonds. Recall that there are no restrictions on acceptor oxygen atoms and, accordingly, only two bonds (which account for the two donor oxygen atoms of the phosphate group) need be specified. As indicated in the figure, there are four oxygen atom sites that are close to and equidistant from the top face of the cube (indicated by asterisks in the oxygen orientation labeling). Each of these four sites must therefore be viable positions for the donor oxygen atom in the upper hydrogen bond. Indeed, the $\mathrm{O}-\mathrm{O}$ distances formed between these oxygen atoms and the equivalent four in the cube above that shown range from 2.46 to $3.03 \AA$ (bonds $2-4$ in Fig. 13b). Similarly, there are four oxygen atoms sites that are equidistant from the bottom face of the cube and that are viable positions for the donors in the downwards directed hydrogen bond. Furthermore, for each possible donor oxygen atom site for the upper hydrogen bond, the phosphate group geometry is such that one of the possible donor oxygen atom sides for the lower hydrogen bond would be part of the specified phosphate group orientation (orientations 1 through 4 in Fig. 13a). That is, the four upper oxygen atom positions are associated with four different phosphate group orientations, where each orientation incorporates one of the four lower oxygen atom positions. Thus, for hydrogen bond configurations in which the bonds extend out of opposing faces of the cube, there are four tetrahedral group orientations possible, if one only considers short hydrogen bonds $\left(\Omega_{\text {tetr }}=4\right)$.

Now let the phosphate group have a hydrogen bond configuration such that one hydrogen bond extends out of the top of the cube in which the phosphate group resides and another one extends to the right. Let us refer to this as an ' $L$ ' configuration of the hydrogen bonds. Once again, there are four clearly viable donor oxygen atom sites for the hydrogen bond extending upwards. There are also four such sites for the hydrogen bond extending to the right. In this case, however, there is not a one-to-one correspondence between the phosphate group orientations implied by these sites. That is, if the phosphate group is placed in any one of the four orientations implied by the four upper oxygen positions, only two of those orientations (orientations 1 and 2) incorporate oxygen atoms close to the right-side face of the cube (indicated by \# in the oxygen atom label). Thus, if only oxygen atoms directly adjacent to a cube face can serve as donors to a bond extending out of that face, then the number of tetrahedral group orientations compatible with ' $L$ ' type hydrogen bond configurations is only two $\left(\Omega_{\text {tetr }}=2\right)$. Noting that there are three possible straight-through configurations of hydrogen bonds and twelve L-type configurations, the weighted average of $\Omega_{\text {tetr }}$ is 2.4. Again, this analysis is restricted to the consideration of short hydrogen bonds in the structure.

Another way in which to consider the tetrahedral group configurational entropy is to include $\mathrm{O}-\mathrm{O}$ linkages that are formed by oxygen atoms not immediately neighboring the cube face of interest. In particular, the bond labeled as bond 1 in Fig. $13 \mathrm{~b}$ represents the linkage of an oxygen atom primarily associated with the top face of the cube so as to form a hydrogen bond through the side face. The $\mathrm{O}-\mathrm{O}$ distance of $2.85 \AA$ falls with the range of bond lengths that can be considered for linkages only via the faces that the oxygen atoms are primarily associated with. In light of this additional possibility for bond formation, one can argue that any of the six orientations is possible with any hydrogen bond configuration and thus $\Omega_{\text {tetr }}=6$. A complexity arises here from the possibility that, for a given hydrogen bond configuration and a given tetrahedral group orientation, there are, in fact, multiple ways in which the pair of donor oxygen atoms can be selected. This is illustrated as follows. Consider the tetrahedral group residing in orientation 6 and the possibility of a straight-through hydrogen bond configuration with the bonds extending 
through the top and bottom faces of the cube. Either of the upper two oxygen atoms associated with this orientation can serve as donors in the hydrogen bond that extends through the top face of the cube (atom labels underlined), if we consider the longer hydrogen bonds. Similarly, either of the lower two can serve as donors in the hydrogen bond than extends through the bottom face of the cube. Because the upper and lower donors can be selected independently, there are four possible ways of assigning the two donor oxygen atoms to conform with hydrogen bonds extending through the top and bottom faces, without changing the orientation of the phosphate group itself. This kind of consideration implies an even greater number of possibilities, specifically, twelve, for L-type hydrogen bond configurations. The weighted average then yields $\Omega_{\mathrm{tetr}}=8.8$, which can be viewed as the maximum number of possible orientations for a liberal cut-off for hydrogen bond formation.

As an intermediate approach, one can retain the possibility of the formation of 'direct' hydrogen bonds of type (1), Fig. 13b, but hypothesize that they are unlikely to form as often as the 'indirect' bonds of type (2)-(4). In a sense, this treats the direct and indirect hydrogen bonds as energetically distinct, but without explicit assignment of energy values. Instead occupation values can be assigned. Doing so yields values of $\Omega_{\text {tetr }}$ intermediate between the 2.4 value obtained when one considers only the direct hydrogen bonds and the 8.8 value obtained when one considers the direct and indirect hydrogen bonds on an equal footing. In particular, a weighting scheme in which the indirect bonds are arbitrarily assigned an occupancy $\frac{1}{2}$ of that of the direct bonds yields a value of $\Omega_{\text {tetr }}$ of 5.2.

Overall, it is apparent there are several defensible ways of assigning a value to $\Omega_{\text {tetr }}$ in superprotonic $\mathrm{CsH}_{2} \mathrm{PO}_{4}$. If one considers the number of possible oxygen positions associated with the formation of a single hydrogen bond it is 4 ; if one considers the number of possible phosphate group orientations it is 6 ; if one considers the number of possible phosphate group orientations compatible with the hydrogen bond configurations it lies between 2.4 and 8.8 , depending on the length of the allowable hydrogen bonds and the weighting scheme employed. Given the difficulty of defining $\Omega_{\text {tetr }}$, it is not possible to use a comparison between the measured and computed values of the transition entropy to validate the proposed interpretation of superprotonic $\mathrm{CsH}_{2} \mathrm{PO}_{4}$. If, on the other hand, we take the approach to be valid, we can used the experimentally measured $\Delta S$ and the computed $\Omega_{\mathrm{H}}$ (for which there is no ambiguity) to evaluate $\Omega_{\text {tetr. }}$. Doing so yields a value of 4.8 , which certainly falls within the wide range anticipated. We tentatively interpret this in terms of the weighting of the short and long hydrogen bonds. Finally, we note that while this discussion does not present a definitive picture of the sources of configuration entropy in $\mathrm{CsH}_{2} \mathrm{PO}_{4}$, it is clear that the hydrogen bond disorder and phosphate group disorder must contribute in some independent fashion to the overall entropy. If these sources of disorder were to be considered entirely correlated such that the orientation of the phosphate group entirely fixed the location of hydrogen bonds, then the number of configurations per formula unit would be only 6 , implying a transition entropy of only $9.13 \mathrm{~J} \mathrm{~mol}^{-1} \mathrm{~K}^{-1}$, far less than the experimentally measured value of $23 \mathrm{~J} \mathrm{~mol}^{-1} \mathrm{~K}^{-1}$.

\section{Summary}

This work provides an overview of the status of the science and technology of solid acid based fuel cells with particular emphasis on $\mathrm{CsH}_{2} \mathrm{PO}_{4}$. On the basis of an evaluation of the literature and our recent conductivity measurements, it is now beyond doubt that $\mathrm{CsH}_{2} \mathrm{PO}_{4}$ undergoes a superprotonic transition at $230{ }^{\circ} \mathrm{C}$. Under typical laboratory climates, dehydration of $\mathrm{CsH}_{2} \mathrm{PO}_{4}$ initiates at temperatures close to the superprotonic transition and thus humidity control is essential to the evaluation of its true physical properties and to the use of this material in functioning devices. Fuel cell measurements to date demonstrate that it is possible to support thin-film $\mathrm{CsH}_{2} \mathrm{PO}_{4}$ electrolyte membranes on porous gas diffusion 
electrodes and obtain peak power densities as high as $415 \mathrm{~mW} \mathrm{~cm}^{-2}$. At this stage, power output is limited by cathode activity rather than membrane conductivity. Indeed for a fuel cell operated at $240{ }^{\circ} \mathrm{C}$ with a $25 \mu \mathrm{m}$ thin membrane, at a current density of $100 \mathrm{~mA} \mathrm{~cm}{ }^{-2}$, the voltage drop across the electrolyte is only $11 \mathrm{mV}$ compared to well over $100 \mathrm{mV}$ across the cathode. The voltage drop across the anode for fuel cells operated on hydrogen is immeasurable. The high temperature of operation of $\mathrm{CsH}_{2} \mathrm{PO}_{4}$ fuel cells has moreover enabled the demonstration of alcohol fueled cells with excellent power output. Further advances in this area will require improvements in the steam reforming catalysts placed within the anode chamber of such fuel cells.

With these results, it is clear that the technological importance of $\mathrm{CsH}_{2} \mathrm{PO}_{4}$ has been proven. While progress in developing commercially viable solid acid fuel cells continues, it is also clear that much of the fundamental physics of this material remain a mystery. Exactly what is the connection, if any, between hydrogen bond disorder and phosphate group disorder? How do these factors play into the remarkable proton conductivity, if at all? And can the answers be used to design materials with even more attractive properties?

\section{Acknowledgements}

This work has been supported by the US National Science Foundation, Division of Materials Research and the US Department of Energy through a subcontract via the DOE-funded Cornell Fuel Cell Institute, of Cornell University.

\section{References}

1 A. I. Baranov, L. A. Shuvalov and N. M. Shchagina, JETP Lett. Engl. Transl., 1982, 36(11), 459-462.

2 A. Pawlowski, Cz. Pawlaczyk and B. Hilzcer, Solid State Ionics, 1990, 44, 17-19.

3 C. Ramasastry and A. S. Ramaiah, J. Mater. Sci. Lett., 1981, 16, 2011-2016.

4 S. M. Haile, D. A. Boysen, C. R. I. Chisholm and R. B. Merle, Nature, 2001, 410, 910-913.

5 A. I. Baranov, V. P. Khiznichenko, V. A. Sandler and L. A. Shuvalov, Ferroelectrics, 1988, 81, 1147-1150.

6 J. C. Slater, J. Chem. Phys., 1941, 9(1), 16-33.

7 M. Komukae, T. Osaka, T. Kaneko and Y. Makita, J. Phys. Soc. Jpn., 1985, 54(9), 34013405.

8 L. H. Rashkovich, K. B. Meteva, Ya. É. Shevchik, V. G. Hoffman and A. V. Mishchenko, Sov. Phys. Crystallogr., 1977, 22(5), 613-615.

9 L. N. Rashkovich and K. B. Meteva, Sov. Phys. Crystallogr., 1978, 23(4), 447-449.

10 E. Rapoport, J. B. Clark and P. W. Richter, J. Solid State Chem., 1978, 24(3-4), 423-433.

11 B. Metcalfe and J. B. Clark, Thermochim. Acta, 1978, 24(1), 149-153.

12 M. Wada, A. Sawada and Y. Ishibashi, J. Phys. Soc. Jpn., 1979, 47(5), 1571-1574.

13 L. C. Gupta, U. R. K. Rao, K. S. Venkateswarlu and B. R. Wani, Thermochim. Acta, 1980, 42(1), 85-90.

14 B. M. Nirsha, E. N. Gudinitsa, A. A. Fakeev, V. A. Efremov, B. V. Zhadanov and V. A. Olikova, Russ. J. Inorg. Chem., 1982, 27(6), 770-772.

15 W. Bronowska and A. Pietraszko, Solid State Commun., 1990, 76(3), 293-298.

16 F. Romain and A. Novak, J. Mol. Struct., 1991, 263, 69-74.

17 R. A. Vargas and E. Torijano, Solid State Ionics, 1993, 59(3-4), 321-324.

18 A. Preisinger, K. Mereiter and W. Bronowska, Mater. Sci. Forum, 1994, 166-169, 511-516.

19 K. S. Lee, J. Phys. Chem. Solids, 1996, 57(3), 333-342.

20 Y. Luspin, Y. Vaills and G. Hauret, J. Phys. I, 1997, 7(6), 785-796.

21 E. Ortiz, R. A. Vargas and B. E. Mellander, J. Chem. Phys., 1999, 110(10), 4847-4853.

22 E. Ortiz, R. A. Vargas and B. E. Mellander, Solid State Ionics, 1999, 125(1-4), 177-185.

23 W. Bronowska, J. Chem. Phys., 2001, 114(1), 611-612.

24 K. S. Lee, Ferroelectrics, 2002, 268, 789-794.

25 J. Otomo, N. Minagawa, C. J. Wen, K. Eguchi and H. Takahashi, Solid State Ionics, 2003, 156(3), 357-369.

26 D. A. Boysen, S. M. Haile, H. J. Liu and R. A. Secco, Chem. Mater., 2003, 15(3), 727-736.

27 J. H. Park, C. S. Kim, B. C. Choi, B. K. Moon and H. J. Seo, J. Phys. Soc. Jpn., 2003, 72(6), 1592-1593. 
28 D. A. Boysen, T. Uda, C. R. I. Chisholm and S. M. Haile, Science, 2004, 303(5654), 68-70.

29 J. H. Park, Phys. Rev. B, 2004, 69(5).

30 K. Yamada, T. Sagara, Y. Yamane, H. Ohki and T. Okuda, Solid State Ionics, 2004, 175(1-4), 557-562.

31 J. Otomo, T. Tamaki, S. Nishida, S. Q. Wang, M. Ogura, T. Kobayashi, C. J. Wen, H. Nagamoto and H. Takahashi, J. Appl. Electrochem., 2005, 35(9), 865-870.

32 A. I. Baranov, V. V. Grebenev, A. N. Khodan, V. V. Dolbinina and E. P. Efremova, Solid State Ionics, 2005, 176(39-40), 2871-2874.

33 E. Ortiz, R. A. Vargas, B. E. Mellander and A. Lunden, Pol. J. Chem., 1997, 71(12), $1797-$ 1802.

34 K. Gesi, J. Phys. Soc. Jpn., 1992, 61(1), 162-167.

35 J. Otomo, T. Tamaki, S. Nishida, S. Q. Wang, M. Ogura, T. Kobayashi, C. J. Wen, H. Nagamoto and H. Takahashi, J. Appl. Electrochem., 2005, 35(9), 865-870.

36 T. Uda and S. M. Haile, Electrochem. Solid-State Lett., 2005, 8(5), A245-A246.

37 H. Gharibi, R. A. Mirzaie, E. Shams, M. Zhiani and M. Khairmand, J. Power Sources, 2005, 139(1-2), 61-66.

38 T. Uda, D. A. Boysen, C. R. I. Chisholm and S. M. Haile, Electrochem. Solid-State Lett., 2006, 9(6), A261-A264.

39 B. A. Peppley, J. C. Amphlett, L. M. Kearns and R. F. Mann, Appl. Catal., A, 1999, 179(1-2), 21-29.

40 C. R. I. Chisholm and S. M. Haile, Chem. Mater., 2006, submitted.

41 Z. Jirak, M. Dlouha, S. Vratislav, A. M. Balagurov, A. I. Beskrovnyi, V. I. Gordelii, I. D. Datt and L. A. Shuvalov, Phys. Status Solidi A, 1987, 100(2), K117-K122.

42 C. R. I. Chisholm, California Institute of Technology, Pasadena, CA, 2002, http:// resolver.caltech.edu/CaltechETD:etd-01292003-150309.

43 H. Matsunaga, K. Itoh and E. Nakamura, J. Phys. Soc. Jpn., 1980, 48(6), 2011-2014.

44 R. J. Nelmes and R. N. P. Choudhary, Solid State Commun., 1978, 26(11), 823-826.

45 K. Imai, J. Phys. Soc. Jpn., 1983, 52(11), 3960-3965.

46 C. R. I. Chisholm, R. B. Merle, D. A. Boysen and S. M. Haile, Chem. Mater., 2002, 14(9), 3889-3893.

47 J. D. Bernal and R. H. Fowler, J. Chem. Phys., 1933, 1(8), 515-548.

48 L. Pauling, J. Am. Chem. Soc., 1935, 57, 2680-2684.

49 W. F. Giauque and M. F. Ashley, Phys. Rev., 1933, 43(1), 81-82.

50 A. V. Belushkin, W. I. F. David, R. M. Ibberson and L. A. Shuvalov, Acta Crystallogr., Sect. B, 1991, 47, 161-166.

51 B. V. Merinov, Crystallogr. Rep., 1997, 42(6), 906-917.

52 B. V. Merinov, A. I. Baranov, L. A. Shuvalov and B. A. Maksimov, Sov. Phys. Crystallogr., 1987, 32(1), 47-57.

53 Y. Yoshida, Y. Matsuo and S. Ikehata, J. Phys. Soc. Jpn., 2003, 72(6), 1590-1591.

54 R. H. Flowers, R. J. Gillespie, E. A. Robinson and C. Solomon, J. Chem. Soc., 1960, $4327-$ 4339.

55 J. S. Bass, R. J. Gillespie and E. A. Robinson, J. Chem. Soc., 1960, 821-836.

56 E. Kanda, M. Yoshizawa, T. Yamakami and T. Fujimura, J. Phys. C: Solid State Phys., 1982, 15(33), 6823-6831. 